\title{
Weighing Diverse Theoretical Models on Turkish Maqam Music Against Pitch Measurements: A Comparison of Peaks Automatically Derived from Frequency Histograms with Proposed Scale Tones
}

\author{
Barış Bozkurt, Ozan Yarman , M. Kemal Karaosmanoğlu \& Can Akkoç
}

To cite this article: Barış Bozkurt, Ozan Yarman , M. Kemal Karaosmanoğlu \& Can Akkoç (2009) Weighing Diverse Theoretical Models on Turkish Maqam Music Against Pitch Measurements: A Comparison of Peaks Automatically Derived from Frequency Histograms with Proposed Scale Tones, Journal of New Music Research, 38:1, 45-70, DOI: 10.1080/09298210903147673

To link to this article: http://dx.doi.org/10.1080/09298210903147673

冓 Published online: 14 Oct 2009.

Submit your article to this journal ๘

Џll Article views: 184

View related articles

Citing articles: 10 View citing articles $\asymp$ 


\title{
Weighing Diverse Theoretical Models on Turkish Maqam Music
}

\section{Against Pitch Measurements: A Comparison of Peaks Automatically Derived from Frequency Histograms with Proposed Scale Tones}

\author{
Barış Bozkurt $^{1}$, Ozan Yarman², M. Kemal Karaosmanoğlu ${ }^{3}$, and Can Akkoç${ }^{4}$ \\ ${ }^{1}$ Izmir Institute of Technology, Turkey; ${ }^{2}$ Istanbul Technical University, Turkey; ${ }^{3}$ Yildiz Technical University, Turkey; \\ ${ }^{4}$ Middle East Technical University, Ankara, Turkey
}

\begin{abstract}
Since the early 20th century, various theories have been advanced in order to mathematically explain and notate modes of Traditional Turkish music known as maqams. In this article, maqam scales according to various theoretical models based on different tunings are compared with pitch measurements obtained from select recordings of master Turkish performers in order to study their level of match with analysed data. Chosen recordings are subjected to a fully computerized sequence of signal processing algorithms for the automatic determination of the set of relative pitches for each maqam scale: f0 estimation, histogram computation, tonic detection + histogram alignment, and peak picking. For nine well-recognized maqams, automatically derived relative pitches are compared with scale tones defined by theoretical models using quantitative distance measures. We analyse and interpret histogram peaks based on these measures to find the theoretical models most conforming with all the recordings, and hence, with the quotidian performance trends influenced by them.
\end{abstract}

\section{Introduction}

In the Middle East, a maqam generally implies a miscellany of rules for melodic composition and improvisation that exhibits diverse characteristics from one geography to another. These rules comprise the tonal/ modal compass, direction (ascent/descent) of the "melodic line' (Touma, 1971), functions of the degrees of the scale(s) and (tri-, tetra-, penta-chordal) genera that are used to construct the scale(s), microtonal inflexions, nuances (vibrato, portamento, etc.) and ornamentations, and possible modulations to or borrowings from other maqams.

It is not our foremost concern to delve in this study into the finer, and in our opinion, more abstract particulars of what constitutes the anatomy of a maqam, as done in Touma (1934/1999) and Powers (1988). We are more concerned with the intended tuning or intonation of a maqam's fundamental scale(s). As such, the so-called 'lifeless skeleton' (Signell, 1977) of a maqam's intricate pitch continuum - which we believe to be no less musically relevant - is substantially important in satisfactorily pinpointing and standardizing 'relatively stable' relative frequency locations on fixedpitch instruments such as qanun, tanbur, lavta and even the more rigid microtonal keyboards.

In the following section, we wish to present a very concise review of the maqam tuning/intonation literature of the past several centuries for readers unfamiliar with the theory of Turkish Maqam music in the hopes that they shall be versed on the influential sources and some established key concepts of this subject matter. For further information, refer to Yarman (2007, 2008), Signell (1977) and Zannos (1990). 
After this, the aims and contributions of this study as well as potential areas of application shall be delineated in Section 1.2. Section 1.3 is devoted to the background and claims of analysed theoretical models. The plan of the manuscript is explained in Section 1.4.

\subsection{A very concise review of edvar/maqam theory sources and some key concepts}

It is well known that maqams, whose denominations are shared by people indigenous to Türkiye, Arab countries, Iran and Transoxania, may not only imply unalike scale structures, but may also be tuned or intoned differently even if they do imply the same. How to tune or intone maqams, known to the ancients as 'edvar' (cycles/modes) and composed of 'ajnas' (tetrachordal and pentachordal genera), has been a controversial theoretical issue for centuries. Islamic Civilization's first music theorist was Al-Kindi (9th century) proposed Pythagorean pitch ratios for Ud fingerings and its complementary Abjad (Arabic ABCD) system of notation. Al-Farabi (10th century) and Ibn Sina (11th century), translated the Hellenic lore on diatonic, chromatic and enharmonic divisions of the diatessaron to the lingua franca that was Arabic at the time in their native land (Yarman, 2007). They made significant contributions to the Islamic theory of music in the manner of rational/just intonation advocates; Archytas, Didymos and Ptolemy (Chalmers, 1992). ${ }^{1}$ Legendary TurkishAbbasid music theorist Safi al-Din Urmavi (13th century) continued this school and also developed a unique 17tones to the octave Pythagorean scale ${ }^{2}$ that was to inspire Rauf Yekta in the 20th century. Abdulkadir Meragi (15th century), musician to the Herat court of Timur the Lame, revived Urmavi's scale in his various tractates. The usage of the term maqamat (pl. maqam) instead of edvar coincides with the lifetime of this famous musician. Somehow, after Meragi, arithmetical calculation of pitches lapsed and did not resurface again for a quadricentennial epoch - though rife with ilm-i edvar (music treatises) - deserving to be titled the 'dark ages of maqam theory'. It is almost as if music theorists had given up trying to pinpoint the relative pitches of maqams and preferred instead the mystical captivation of esoteric chirography. Similarly, during the late Ottoman Era, Dimitrie Kantemir, Nayi Osman Dede, Tanburi Küçük Harutin (all 18th century), Abdulbaki Nas ir Dede, and Hamparsum Limonciyan (both 19th century) developed distinctive pitch notations without as much as a numerical

\footnotetext{
${ }^{1}$ Also cf. 'diatonic genus', 'chromatic genus' and 'enharmonic genus' in Tonalsoft Encyclopedia of Microtonal Music-Theory by Joseph Monzo, and compare with Ibn Sina, ca. 1030/2004. ${ }^{2}$ This scale is constructed via a chain of 4 fifths up and 12 fifths down from the tone of origin.
}

indication to their intended tuning/intonation. The awakening in tangible musical mathematics recommenced with Mikhail Mushaqah of Lebanon (19th century) and reached an apex with modern Turkish music theorists Rauf Yekta, Saadettin Arel and Suphi Ezgi of 20th century Türkiye (Yarman, 2008).

We chance upon maqam names similar to the ones used today in works of the Islamic theorists mentioned above. For instance, we observe such names as Isfahan and Selmeki in Ibn Sina (ca. 1030/2004), and Uş̧ak, Neva, Rast, Isfahan, Rahavi, Zirafkand and Buzurk in Urmavi (Arslan, 2007) as we read the chapters on the construction of genera and scales.

Remember, that the ancients called genera ajnas and scales edvar. To provide an explicit picture of these ancient building blocks predating today's tetrachords/ pentachords and maqams, let us deliberate on, for example, Rahavi, which is a peculiar tetrachordal genus described by Urmavi as 16:15 omitted 16:15 $\times 15: 14 \times$ $14: 13 \times 13: 12$, yielding the following scale:

$\begin{array}{lrll}1 / 1 & 0.000 & \text { unison, perfect prime } & \\ 16 & 114.731 & & \\ 8 / 7 & 231.174 & \text { septimal whole tone } & (\times 16: 15) \\ 16 / 13 & 359.472 & \text { tridecimal neutral third } & (\times 14: 13) \\ 4 / 3 & 498.045 & \text { perfect fourth } & (\times 13: 12)\end{array}$

This genus is resemblant of quotidian Arabic rendition of the cadence region of maqam Segah extended toward the bass if the finalis was ascribed to 16/13. However, this is a bit of a stretch, since Safi al-Din defines the Rahavi genus elsewhere in his al-Risalat alSharafiyya (Arslan, 2007) as the confluence of three mujannab-i sebbabe (anterior index finger position on the $u d$ ) intervals totalling 5:4, it is more proper for Rahavi to be constructed in reverse, yielding a Perso-Arabic rendition of the Saba diminished tetrachord with a semi-tonal second degree as shown below:

$\begin{array}{lrll}1 / 1 & 0.000 & \text { unison, perfect prime } & \\ 13 / 12 & 138.573 & \text { tridecimal 2/3-tone } & (\times 13: 12) \\ 7 / 6 & 266.871 & \text { septimal minor third } & (\times 14: 13) \\ 5 / 4 & 386.314 & \text { major third } & (\times 15: 14) \\ 4 / 3 & 498.045 & \text { prfe } & (\times 16: 15)\end{array}$

Note that Urmavi defines on the $u d$ 'mujannabat' (the three possible mujannab-i sebbabe intervals) as 18:17 (99 cents), 162:149 (145 cents) and 54:49 (168 cents) respectively. Moreover, 65536:59049 (180 cents) should be counted as another mujannab interval according to the 17-tone Pythagorean tuning.

On the $u d$, the finger positions for Rahavi are hinted as:

1. Open string ( 0 cents),

2. Anterior index finger $(99,145,168$ or 180 cents), 
3. Middle finger known to the ancients (the Pythagorean minor third at 32/27, making 294 cents),

4. The ring finger (the Pythagorean major third at $81 /$ 64 , making 408 cents and one syntonic comma larger than 5/4).

We find the Rahavi genus (in bold typeface) in the devir of Rahavi, which-when interpreted within the 17-tone Pythagorean tuning-yields the following scale:

$\begin{array}{lrl}\text { 1/1 } & 0.000 & \text { unison, perfect prime } \\ 65536 / 59049 & 180.450 & \text { Pythagorean diminished third } \\ \mathbf{8 1 9 2 / 6 5 6 1} & \mathbf{3 8 4 . 3 6 0} & \text { Pythagorean diminished fourth } \\ \mathbf{4 / 3} & \mathbf{4 9 8 . 0 4 5} & \text { perfect fourth } \\ \mathbf{2 6 2 1 4 4} / \mathbf{1 7 7 1 4 7} & \mathbf{6 7 8 . 4 9 5} & \text { Pythagorean diminished sixth } \\ \mathbf{1 2 8} / \mathbf{8 1} & \mathbf{7 9 2 . 1 8 0} & \text { Pythagorean minor sixth } \\ 16 / 9 & 996.090 & \text { Pythagorean minor seventh } \\ 2 / 1 & 1200.000 & \text { octave }\end{array}$

The Pythagorean apatome at 2187:2048 (114 cents) occurs in the above rendition of the Rahavi genus twice and functions as another mujannab. It can be derived from partitioning the Pythagorean minor third (32:27) into two parts, the other of which is 65536:59049 at 180 cents. Given that Pythagorean augmented prime falls between 99 and 145 cents and Safi al-Din requires two mujannabs (in this case, $114+180$ cents) plus one limma (90 cents) to complete a tetrachord, it is doubly requisite to call 114 cents a mujannab interval also.

Whilst preserving the mujannab +mujannab+ mujannab structure and the character of the Saba diminished tetrachord with a semi-tonal second degree, ${ }^{3}$ Rahavi genus can be re-defined in the following manner:

$\begin{array}{lrl}1 / 1 & 0.000 & \text { unison, perfect prime } \\ 2187 / 2048 & 113.685 & \text { apotome } \\ 32 / 27 & 294.135 & \text { Pythagorean minor third } \\ 81 / 64 & 407.820 & \text { Pythagorean major third }\end{array}$

Maximum absolute difference between any degree of the two renditions of the Rahavi genus is no more than 31 cents.

Other genera also have some semblance to quotidian maqams. Zirafkand-i Koutchek, which is a pentachord first given as $14: 13 \times 13: 12 \times 36: 35 \times 8: 7 \times 35: 32$, but quickly revised by Urmavi as $14: 13 \times 13: 12 \times 36: 35 \times$ $9: 8 \times 10: 9$, yields the following scale:

$$
\begin{array}{lrll}
1 / 1 & 0.000 & \text { unison, perfect prime } & \\
14 / 13 & 128.298 & \text { 2/3-tone } & (\times 14: 13) \\
7 / 6 & 266.871 & \text { septimal minor third } & (\times 13: 12)
\end{array}
$$

\footnotetext{
${ }^{3}$ This would imply Saba Zamzama instead of Saba. Note, that Zamzama is synonymous with a half-tone + whole-tone + halftone diminished tetrachord in modern Arabic Maqam music theory.
}

$$
\begin{array}{llll}
6 / 5 & 315.641 & \text { minor third } & (\times 36: 35) \\
27 / 20 & 519.551 & \text { acute fourth } & (\times 9: 8) \\
3 / 2 & 701.955 & \text { perfect fifth } & (\times 10: 9)
\end{array}
$$

Following Urmavi's mujannab + mujannab + limma structure for Zirafkand genus and the instructions for allowing for the presence of two 5:4s, we understand that this pentachord ought to be reversed and all pitches after 5/4 omitted:

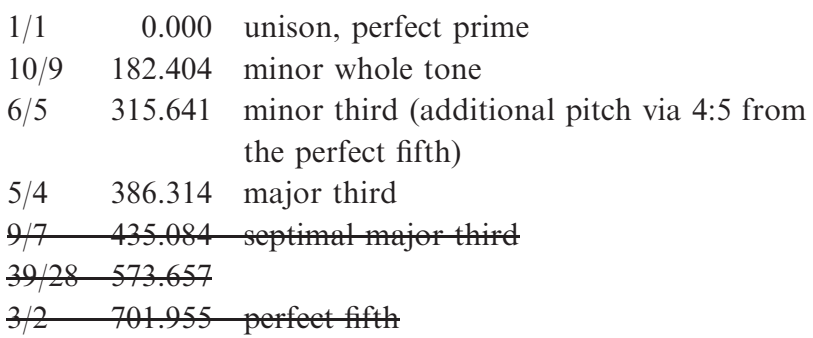

Zirafkand genus employs the same $u d$ finger positions as Rahavi, save the final degree of the trichord, which is Zalzal wosta (middle finger) at 27/22 (355 cents). If we are to account for the limma (256:243 at 90 cents) a higher middle finger is implicated:

$\begin{array}{lrl}1 / 1 & 0.000 & \text { unison, perfect prime } \\ 162 / 149 & 144.818 & \text { Persian neutral second } \\ 32 / 27 & 294.135 & \begin{array}{l}\text { Pythagorean minor third } \\ \text { 8192/6561 }\end{array} \\ 384.360 & \begin{array}{l}\text { Pythagorean diminished fourth } \\ \text { (corrected Zalzal wosta) }\end{array}\end{array}$

Notice that there is a 149 cent interval expressible as 2187:2384 which resides between $162 / 149$ and $32 / 27$. This interval is very close $162 / 149$ and constitutes another possible mujannab interval, though not strictly defined as such.

Urmavi gives a mujannab + mujannab + wholetone + mujannab + mujannab + limma + wholetone + mujannab scale for the devir of Zirafkand that contains the Zirafkand genus in bold. This scale is produced below in 7-limit Just Intonation with the Zirafkand genus in bold:

$\begin{array}{lrl}\text { 1/1 } & 0.000 & \text { unison, perfect prime } \\ 49 / 45 & 147.428 & \text { Bohlen-Pierce minor semitone } \\ 32 / 27 & 294.135 & \text { Pythagorean minor third } \\ \mathbf{4 / 3} & \mathbf{4 9 8 . 0 4 5} & \text { perfect fourth } \\ \mathbf{1 9 6 / 1 3 5} & \mathbf{6 4 5 . 4 7 3} & \\ \mathbf{1 2 8 / 8 1} & \mathbf{7 9 2 . 1 8 0} & \text { Pythagorean minor sixth } \\ \mathbf{5 / 3} & \mathbf{8 8 4 . 3 5 9} & \text { (Bohlen-Pierce) major sixth } \\ 15 / 8 & 1088.269 & \text { classic major seventh } \\ 2 / 1 & 1200.000 & \text { octave }\end{array}$

Errors amounting to a maximum absolute of 33 cents per degree would result were we to render the Zirafkand devir in the 17-tone Pythagorean scale of Safi al-Din Urmavi: 


$\begin{array}{lrl}1 / 1 & 0.000 & \text { unison, perfect prime } \\ 65536 / 59049 & 180.450 & \text { Pythagorean diminished third } \\ 32 / 27 & 294.135 & \text { Pythagorean minor third } \\ \mathbf{4 / 3} & \mathbf{4 9 8 . 0 4 5} & \text { perfect fourth } \\ \mathbf{2 6 2 1 4 4} / \mathbf{1 7 7 1 4 7} & \mathbf{6 7 8 . 4 9 5} & \text { Pythagorean diminished sixth } \\ \mathbf{1 2 8} / \mathbf{8 1} & \mathbf{7 9 2 . 1 8 0} & \text { Pythagorean minor sixth } \\ \mathbf{3 2 7 6 8 / 1 9 6 8 3} & \mathbf{8 8 2 . 4 0 5} & \text { Pythagorean diminished seventh } \\ 4096 / 2187 & 1086.315 & \text { Pythagorean diminished octave } \\ 2 / 1 & 1200.000 & \text { octave }\end{array}$

The fact that errors are rather marginal for Zirafkand and Rahavi $^{4}$. leads us to conjecture that the said 17-tone tuning is merely a flexible fretting guideline for the $u d$ with minimal number of tones versus smallest intervallic deviations for various mujannab (middle second) intervals.

Here, we might quote from Dr. Albrecht Schneider (article review, 26 March 2009 [email]):

... I would say that this ['classical' Persian/Arabian tone system as outlined, probably best of all, by Safi al-Din] basically is a system derived from Pythagorean tradition that, however, is expanded by a very simple yet very effective operation: continue a sequence of pure fifths that starts from a certain tone into both directions (up, down). If you continue this operation long enough (up to 12 fifths in a row), and put back all the tones you have found by this operation into one octave (or, alternatively, into two octaves structured into tetrachordal patterns), you will gain a very elaborated tone system suited to serve as the foundation of several actual tuning options (i.e., selections of pitches per octave depending on where you put your frets on a longnecked lute).

As one proceeds further in history to the era of Meragi, one soon realizes the futility in drawing direct parallels between 15 th century scales with today's maqams, since the elaborate arithmetical divisions of tetrachordal and pentachordal genera of the earlier generations are all but abandoned by the music theorists. We witness only the repetition of Urmavi's 17-tone Pythagorean tuning, the Abjad notation it curtails, and explication of maqams/ avazes/şubes/terkibs via this tone-system and its notation.

Eventually such endeavours too are abandoned by the end of the 15th century. We are left clueless about how pitch inflexions occur or if they occur at all throughout the extent of the 'dark ages of maqam theory'.

Take for instance 'Risale-i Musiki' by Nizameddin ibn Yusuf of Kurşehir (Sezikli, 2000), where we find Zirefkend-Kuçek attributed to the zodiac sign of Cancer and the element of water followed by a cryptic circle where supposedly pitches of the said devir is given. Here, Nizameddin is more concerned with which maqams are

\footnotetext{
${ }^{4}$ We have chosen Zirafkand and Rahavi for demonstration purposes, because they are two rare maqams that Urmavi gives both the genera and the edvar for.
}

implied when the tonic changes among the few tell-tale perdes (notes or tones) he provides.

From this point forward until the 18th century, as the number of maqams/avazes/şubes/terkibs increase with treatise after treatise, a modern researcher's confusion abounds as to which denomination comprises what scale(s). Esoterism has crept in to replace the genuine mathematical approach of Urmavi during the 'dark ages of maqam theory'. A similar situation is true for the music theory of the Greek Orthodox Church within the borders of the Ottoman Empire, where 'all teaching is done by ear' (Zannos, 1990).

By the 18th century, a significant change has occurred. In the treatise of Dmitri Kantemir (1698), we are relieved to find that maqams are explained by a sequence of intelligible perdes similar to the ones in effect today such as segah, buselik, acem, sünbüle etc. Take for instance the definition of Zirefkend:

Explanation of the so-called maqam Zir-efken(d): Maqam Zirefken $(d)$ is explained in two ways. Some say that it starts at muhayyer [e'] and concludes on asiran [B]. Others claim that it starts at tiz hüseyni [b'] and concludes on dügah [e].

Should it start its sonic course from muhayyer [e'], it descends via whole perdes ${ }^{5}$ [d', ct', $\left.b, a\right]$ on to cargah [g], and then - after stepping on buselik [f\#]-suddenly falls down to rast [d] [by skipping dügah-e]. From thereon-with the perde irak [c†]-rests on the post of aşiran [B]...

Should it start its sonic course from tiz hüseyni [b'], it descends to gerdaniye [d'] over whole perdes [a', g', etc.] from the face of sünbüle [f']. From thereforward, it steps on perde acem [c'] by omitting perde evc [ct'] and-after descending by whole perdes through hüseyni [b], neva [a], cargah $[g]$ and segah [f $]$-concludes on perde dügah [e].

While this style of describing a maqam lacks any mathematical foundation and even so has little or nothing to do with Urmevi's Zirafkand, it is at least more lucid than the cryptic scribbles of the previous centuries.

Zir-efkand-i Kucek of the old treatises is also elucidated by Kantemir in a similar manner, though yielding nothing resemblant of Urmavi's genus of the same name. Rehavi, on the other hand, resembles the Rahavi genus:

Rehavi: Having drawn perde neva [a] very near to perde çargah [g] and starting its movement from there [ab], comes to perde dügah [e] after stopping by perdes cargah [g] and segah [f $\$$ ]. It concludes on perde dügah [e] while also

\footnotetext{
${ }^{5}$ Natural diatonic or 'whole' tones (tam perdeler) in contrast to half-tones (nim perdeler). These are the only indications Kantemir and later Ottoman theorists provide for the distances between perdes. Notice the similarity between maqam names and perde names. A perde is named after a maqam because it is a crucial functional degree for that maqam.
} 
stepping on the nim perde [zirgule/zengule — d\#] below dügah. ${ }^{6}$

While this definition of the old Rehavi partially conforms with Urmevi, the contemporary Rehavi of Kantemir is: 'nothing but a Rast maqam imitating the melody of the trumpet.' An examination of Dede Efendi's Rast Kar-l $N_{a t \imath} k^{7}$ in the early 19th century will validate the employment of a Rehavi cadential phrase that indeed is none other than an arpeggiating Rast.

We find a more proper definition of Zirefkend-i Kucek in Kemani Hızır Ağa (Daloğlu, 1985), who, a few decades later and using the same eloquent descriptive style as Kantemir, implies that the maqam in question is a descending version of Saba using the perdes gerdaniye, evc, hüseyni, nim (half-tone of) saba, cargah, segah and dügah; a clarification which agrees almost entirely with Urmavi's Zirafkand.

The kinship between Saba, Zirefken(d) and Kucek is soon attested by Abdulbaki Nasir Dede (Nasir, 1796). This fact is emphasized much later by Suphi Ezgi (1940) and Yakup Fikret Kutluğ (2000).

Today, Urmavi's Zirafkand could be said to survive as maqam Kuçek, and Rahavi as maqam Saba Zemzeme. Future investigations will certainly reveal the similarities or differences between ancient edvar and later maqams.

We now conclude our short historical excursion with the theoretical developments in the 20th century.

Since the early 20th century, various theories have been proposed in Türkiye in order to explain and notate maqams. Each theory is based on a tuning that is at odds with the others. The 24-tone Pythagorean tuning devised by Rauf Yekta (1922/1986) and modified by Saadettin Arel, Suphi Ezgi and Murat Uzdilek is widely recognized as the official model. It is, for all intents and purposes, an extension of Urmavi's 17-tone Pythagorean scale (Yarman, 2008). The Arel-Ezgi-Uzdilek (AEU) theory (Arel, 1930/1968; Ezgi, 1933) built upon this model and taught in Turkish Music conservatories since 1943 is rivaled by a theory based on a 41-tone subset out of 106 equal divisions of the octave formulated by Abdulkadir Töre and Ekrem Karadeniz (Karadeniz, 1965/1983). However, Töre-Karadeniz (TK) has never gained a significant following in Türkiye. In the last few decades, the method of partitioning the whole tone into 9 and the octave into 53 commas has spread among traditionalist circles. Division of the octave into logarithmically 53 equal parts known as Holderian commas ${ }^{8}$ also embodies the

\footnotetext{
${ }^{6}$ The Western note-names are those used by Yalçın Tura.

${ }^{7}$ An instrumental-vocal form of composition meant for music education that demonstrates many maqams one after the other.

${ }^{8} \mathrm{We}$ have been informed by our second reviewer Dr. Albrecht Schneider that this comma of 22.64151 cents is wrongly attributed to William Holder. It was actually
}

24-tone Pythagorean tuning with less than a cent error (Yarman, 2007). According to this approach, accidentals of the AEU system are said to deviate from their original positions by comma steps for certain maqams. A special music notation program called 'Mus2' exploits the Holderian comma resolution when interpreting AEU accidentals and rises as a contender. Doubling the pitch detail of the Arabic quarter-tone system is a recently published treatise where maqams are tuned according to logarithmically 48 equal divisions ${ }^{9}$ of the octave (Yavuzoğlu, 2008). Lastly, a novel 24-tone tuning is introduced by the second author as an alternative to the AEU system (Yarman, 2009).

\subsection{Background and claims of modern theoretical models}

The background and claims of analysed theoretical models regarding the tuning/intonation of perdes and the reliability with which they represent Turkish Maqam music on paper is an issue that must be addressed shortly at this point.

We observe that Rauf Yekta admitted to the usage of such intervals as the diminished minor tone (12:11 at 151 cents), augmented apotome (15:14 at 119 cents), and augmented limma (135:128 at 92 cents) that his 24-tone Pythagorean tuning did not account for (Yekta, 1929).

discovered by a Belgian Engineer named Jean Galle as reported by Marin Mersenne in 1637. Nicolaus Mercator gave a more mathematically precise description of the said comma in 1660 . We also observe that Alexander J. Ellis calls the 53-tone equal temperament yielding this artificial comma 'Mercator's cycle' (Helmholtz, 1877, pp. 328-329, 436). 'Mercator's cycle' appears afterwards in Isaac Newton's unpublished manuscripts dated 1664-65 and William Holder's treatise of 1684. (cf. Barbieri, 2008). We reproduce this information with permission of and special thanks to our reviewer Dr. Schneider who was generous enough to disclose his identity (emails dated 26 March and 29 April 2009). Due to the fact that this comma is known widely in Turkish Maqam music circles as the Holderian comma despite attempts to call it other names (cf. Uysal, 2001, pp. 49, 60, 122, 144 ['uygun'], and Aksoy, B. Makam in Tan im ina Doğru. Musıkişinas, 7. İstanbul, 2000, pp. 70-87 ['minik', suggested by Mildan Niyazi Ayomak]), and since William Holder partook in the promulgation of it, we shall keep referring to it as the Holderian comma $(\mathrm{Hc})$ in our study. ${ }^{9}$ The first person to employ $1 / 8$ tones to explain modern Turkish genera and maqams is Edward J. Hines. Through personal communication, the second author has learned that $\mathrm{Mr}$. Hines has chosen 48-tone equal temperament to notate maqams as early as 1989 (Hines, 2009; through private email communication with the second author, 3 May 2009). This information was obtained after the main body of the article was completed; hence, Mr. Hines' approach was not included in the manuscript. 
While the latter two might be dismissed for their extreme proximity to the apotome (114 cents) and the limma (90 cents), the nakıs büyük mücenneb given as 12:11, which Yekta acknowledges to be indispensable to achieve the last degree of the Saba diminished tetrachord, cannot be brushed aside so easily. If this interval was approximated by the apotome as Yekta allowed, the error would be as high as 37 cents. If it was rounded to the minor tone at 180 cents as Yekta says some musicians inclined to, the error would be 29 cents and the effect far removed from that of the apotome. Yekta calls these errors 'minute'; however, in a tuning where half the number of tones are placed a comma apart from the other half (Signell, 1977), these errors could be anything but 'minute'. Though he is confident that the 24-tone Pythagorean tuning suffices to represent all maqams faithfully and that no additional fret is needed in the case of 12:11, it is evident that Yekta was promoting a tone-system which did not comprise all the mujannabat so clearly defined by Urmavi on the $u d$ centuries ago.

Yekta's followers, Arel and Ezgi, concerned not to provoke the newly founded nation-state poised-for the sake of the Turkification of culture - to abolish any references to the quarter-tones so confidently associated with the Byzantine and the Arabs, were even more eager, alas in vain, to bludgeon nonconforming intervals into the framework of the 24-tone Pythagorean tuning. ${ }^{10}$ For example, Suphi Ezgi, who admitted to the usage of 11:10 (165 cents) between dügah and segah in maqam Uş̧ak in 1933 (Ezgi, 1933) back-pedalled in 1940 (Ezgi, 1940) and corrected the ratio to $125: 113$ (175 cents), finally approximating that with 65536:59049 (180 cents). Rauf Yekta's slogan: 'there are no quarter-tones in Turkish music' (Erguner, 2003) became Arel's watchword after he rose to the position of director of Istanbul Conservatory with special privileges. Soon enough, AEU was elevated to the 'national theory of Turkish music'; its pitches rock-steady, unmoving ... defying a myriad of mujannab intervals executed in actual practice.

This state of affairs continued for a long time, until, by the late 1980s, comma steps arising from the partitioning of the whole-tone into 9 parts ${ }^{11}$ began to be employed to distinguish nonconforming perdes in such maqams as Uşsak, Saba, Karciğar and Hüzzam; a procedure that effectively broke the barriers of AEU and led musicians to embrace the 53 commas per octave resolution in which AEU became a subset. Nevertheless, dichotomy between

\footnotetext{
${ }^{10}$ For a synopsis of the role of the 24-tone Pythagorean tuning and theory in light of events and ideologies that led to the ban on the education of Turkish Maqam music instruments and the prohibition of Alla Turca broadcasts during 1934-1936, cf. Yarman (2009).

${ }^{11}$ Initially, a short-hand for the demonstration of comma, limma, apotome and minor tone positions within the wholetone.
}

this resolution and the old AEU notation persists even today despite attempts such as the 'Mus2' approach (cf. Appendix) to mitigate it.

Töre-Karadeniz was developed at a time when the AEU theory was reigning supreme. With 41 tones per octave at its arsenal, this new theory-whose foundations are said to be laid by Abdulkadir Töre in the early 20th century if we are to believe Ekrem Karadeniz - was prepared to account for the unruly perdes of Turkish Maqam music. However, due to its irregular nature and the difficulty with which it was shown on paper, the theory soon lost its allure and was entirely abandoned in favour of the 53 commas per octave methodology. The remaining supporters of Karadeniz's treatise were dealt a deadly blow by music theorist Ayhan Zeren (2003), who is even today a staunch advocate of the AEU system. Although, the psycho-acoustics of the treatise is poor in language, science, and facts, the 41-tone subset out of logarithmically 106 equal divisions of the octave merits evaluation, and hence, was included in our study.

With TK out of the way, more alternatives came to the scene. Nail Yavuzoğlu, educated in Classical Western music and Jazz and nurturing a special interest towards Turkish Maqam music theory, thought up dividing the octave into 60 equal parts at first (Yavuzoğlu, 1991) but later settled with 48 equal parts (Yavuzoğlu, 2008). While devising temperaments that are multiples of logarithmically 12 equal divisions of the octave is nothing original, this new theory deserves to be investigated, especially concerning its claims to truly represent problematic perdes of such maqams as $U_{\text {ş̧ }}$, Saba and Hüzzam.

A final contender boasting 24 pitches to the octave was proposed by the second author as an alternative to the AEU system using the same microtonal symbols and capable, according to Dr. Yarman, of adequately explaining all maqams in a single ahenk (diapason) with all due reservations as to a performer's choice of microtonal inflexions for free-pitched instruments.

\subsection{The aims and contributions of this study including potential areas of application}

The diversity of so many tuning schemes for Turkish Maqam music necessitates their comparison with frequency measurements obtained from actual recordings to evaluate their success in representing practice. In the words of Iannis Zannos (1990):

... from a contemporary standpoint, theory should be regarded as an integral part of musical tradition, and its relationship to other kinds of historical or contemporary evidence about musical practice should be carefully examined...

In the 19th and 20th century, within the general framework of cultural changes and crises in traditional arts, music theory underwent radical reforms in both Greece and 
Turkey. Once more, the subject of the definition of intervals - that is of correct intonation - was taken up, and several proposals were made. None of them offers a perfect solution; even more, none of them can be said to correspond with contemporary empirical study, in the current more advanced state of physical measurement and mathematical modelling.

In this study, we echo these concerns and apply recently developed automatic frequency analysis techniques (Bozkurt, 2008) to recordings of venerable masters of Turkish Maqam music and undertake a study, for the first time in the literature, to assess how well the abovementioned theoretical models reflect practice for a given audio collection and the quotidian performance tradition influenced by that collection.

The automatic analysis system explained in this article accepts an audio file in a given maqam as input and produces an optimum set of relative pitches for the given maqam. These pitches will be compared with the pitches of maqam scales tuned according to suggested theories.

Our pursuit, if we may say so, is not really much different in essence than the hypothetical case of an extraterrestrial team of researchers attempting to pinpoint an ideal and uncumbersome tone-system for a corpus of instrumental and vocal Classical Western music transmissions notwithstanding how crudely or unwholesomely the resultant tuning scheme (which assuredly would turn out to be 12 equal tones per octave or a sibling cyclic temperament) would represent the intended music.

There are many studies that mention the existence of mismatches between the intervals executed by master musicians and those specified in the Arel-Ezgi-Uzdilek (AEU) theory (Arel, 1930/1968; Ezgi, 1933). ${ }^{12,13}$ However, most of these studies either imply an unsubstantiated 53 commas to the octave methodology (Özkan, 1998) or are based on pitch determinations deduced from limited data (Karaosmanoğlu \& Akkoç, 2003; Tulgan, 2007; Yarman, 2008). The main reason for this is the lack of reliable analysis methods. Despite the existence of abundant signal processing algorithms for Western

\footnotetext{
${ }^{12}$ Cf. Signell, 1977; also Zannos, 1990: 'Using a limited number of degrees is a theoretical concession which inevitably results in disregarding certain details of intonation.'

${ }^{13}$ Admittedly, the utilization of 12-tone equal temperament or a sibling tuning in keyboard and fretted instruments in Classical/ Contemporary Western music is not in the least unacceptable, namely, one can perform a piece written for trombone or violin on a piano without grossly misrepresenting or distorting the intended music, whereas, fretting the tanbur or affixing mandals on a qanun strictly according to the 24-tone Yekta-Arel-EzgiUzdilek tuning will be disastrous for Maqam music performance; namely, this tuning scheme will grossly misrepresent or distort the intended music, particularly for maqams or modulations to Saba, Uşsak, Hüzzam, Karcı̆̆ar, etc., where the margin of error for certain tones is very narrow.
}

music, direct application of such methods to Turkish Maqam music and/or developing automatic analysis methods therefrom is not practicable due to the indispensable characteristics of maqams: it is well known that perdes (notes or tones) of maqams do not always correspond to fixed pitches; that is to say, dozens of maqams employ a large variety of microtones and musicians may differently interpret certain degrees of maqam scales. ${ }^{14}$ In addition, the concept of absolute pitch is meaningless as there are 12 possible diapasons (called 'ahenk'). These are significant obstacles in the development of an automatic analysis system that is capable of processing multiple recordings.

In a recent study (Bozkurt, 2008), a new algorithm was proposed that can overcome said difficulties by aligning frequency histograms acquired from different recordings in an iterative manner. In this article, we present the application of that algorithm to a database of select recordings with the aim of comparing them and the following theoretical models:

(1) Yekta-Arel-Ezgi-Uzdilek (YAEU), taken together since it has been shown in Yarman (2007) that AEU (Arel, 1930/1968; Ezgi, 1933) is no more than a simple modification of the original 24-tone Pythagorean tuning of Yekta (1922/1986);

(2) 'Mus2' is explained further in the Appendix section which uses AEU notation and extends its tone resolution to logarithmically 53 equal divisions of the octave;

(3) Töre-Karadeniz (TK) based on a 41-tone subset out of logarithmically 106 equal divisions of the octave;

(4) an alternative approach featuring a novel 24-tone tuning suggested by the second author referred to as Yarman24 (Yarman, 2009);

(5) a recent theory based on logarithmically 48 equal divisions of the octave referred to as Yavuzoglu48 (Yavuzoğlu, 2008).

While there are more theoretical models for Turkish Maqam music such as a 29-tone tuning by Gültekin Oransay (1959), a subset of 72-tone equal temperament universally applied to Turkish qanuns since the widespread utilization of 12 equal semitones per octave temperament tuners imported from the West, 65-tone equal temperament elaborated very recently by the grandson of Rauf Yekta, Mehmet Yektay as a mandal ${ }^{15}$ affixture scheme for qanuns, and a 79-tone tuning

\footnotetext{
${ }^{14}$ For example, Zannos (1990) acknowledges: 'The key problem of the diatonic species is a very old one: the position of the degree segah (vou)... Today, some schools prefer a higher position, some a lower one...'

${ }^{15}$ Metallic levers arrayed across the diagonal side of the qanun that serve to alter vibrating lengths of the courses on the fly by an amount foreordained at the time of their installation.
} 
proposed elsewhere by the second author and implemented on a unique qanun (Yarman, 2008), we have chosen only the aforesaid five models for comparative evaluation. Our choice depends on the criteria that the maximum number of tones per octave is no more than 53 , and that notations of works in the given tunings exist unless they were very recently proposed. Since the number of tones per octave in the 72-tone and 79-tone models exceed 53, and works have not been notated in these tunings and even in the less voluminous Oransay29, they were all dismissed. Yavuzoğlu48 and Yarman24 were included despite the fact that they lack a repertory because they were newly conceived.

Although there are predecessors to our study where frequency measurements of Turkish Maqam music instruments or recordings were accomplished such as in Signell, (1977) ${ }^{16}$ and Yahya (2002), ${ }^{17}$ we can confidently say that none of them is as comprehensive and methodical as our work.

The findings of this study are potentially applicable to the solution of practical problems of Turkish Maqam music like the clarification of the rudiments of maqam intonation - such as which degrees of a maqam scale exhibit how much inflexion or fuzziness-so as to facilitate the standardization of fixed-pitch instruments such as tanbur and qanun. Since the theory in effect has apodictic shortcomings, instrument makers assign frets and mandals according to demand or as they see fit. As a consequence, some instrumental tractates provide alternative fret locations for the very same instrument. For example, in Akan (2007) frets are given not just according to AEU theory, but also according to this or that musician. Clarity of intonation in large instrumental ensembles is particularly troublesome for this very reason.

Analysis of empirical data would thus help future development of a theory more compatible with Turkish Maqam music practice, which in turn would aid the afore-mentioned standardization process. Implementation of such a theory to music education could serve as a basis for the elucidation of the seyir or melodic procedure/progression phenomenon which is so crucial to understanding maqams.

\footnotetext{
${ }^{16}$ Where Karl Signell measures intervals between perdes fretted by tanbur virtuoso Necdet Yaşar not defined in AEU theory.

${ }^{17}$ Where Gülçin Yahya takes the total percentage of each counted perde executed in an ud taksim (improvisations) of Yorgo Bacanos using Steinberg WaveLab (we do not know how she ascertains a perde's frequency) and compares that to the percentage of note lengths in her hand-transcriptions of that taksim. This operation demonstrates either the failure of the ear (or at least the author's ear) to determine correct note durations, or the hazard of incorrectly identifying a perde's frequency value for comparison with its heard counterpart, or both.
}

In addition, algorithms such as the automatic recognition of the maqam of a recorded musical piece and the automatic note transcription therefrom would work much better if the theoretical information provided by the tuning was more conforming with practice. Our achievements could lead to the hands-free transcription and, in favourable tunings, playback of Turkish Maqam music recordings by computer notation/sequencer software armed with sampled instrument sounds that closely reflect or mimic actual practice. ${ }^{18}$

\subsection{Plan of the manuscript}

Our study comprises the following steps explained in detail in subsequent sections: first, a database of acclaimed performers is compiled and master executants are chosen from the literature. For example Tanburi Cemil Bey's recordings are included, since they are considered in various documents such as Tanrikorur (2004) to be the leading examples for famous musicians like İhsan Özgen, Necdet Yaşar, and Ercument Batanay. As the second step, fundamental frequency (f0) estimation is performed and post-filters are applied to correct the estimations. From the f0 data, pitch histograms are computed. Then we employ an automatic tonic detection algorithm which attempts to align a YAEU maqam scale template with the stalagmitic shape of each histogram to initially line up histograms with respect to each other. In an iterative manner, the maqam scale template is reconstructed from the lined up histograms and template-histogram alignments are re-performed. Then, histograms from multiple files are combined for each maqam based on their tonics. As a result, overall histograms are obtained in each maqam category. These histograms are further processed to yield the peak values, which are plotted together with the scale tones of YAEU, Mus2, TK, Yarman24 and Yavuzoğlu48 to provide opportunity for visual comparison.

In addition to the histogram plots used for visual comparison, we also provide quantitative distance information obtained by calculating how far theorized scale tones lie from histogram peaks and taking averages for each tuning. This facilitates the ranking of tunings from best to worst according to their match with measured data, and thus, in a limited sense, with Traditional Turkish music practice. Because scale tones for each maqam according to each theoretical model shall be given in Hc and cents, we shall not concern ourselves with how maqams are constructed and what type of seyir (procedure) they need to follow; information pertaining to these can be obtained from already published treatises.

\footnotetext{
${ }^{18} \mathrm{~A}$ step toward this direction has already been taken by the third author in his novel publication of a Turkish Music Multimedia Encyclopedia called 'Mus2okur' (www.musiki. org).
} 
Finally in Sections 5 and 6, we present a detailed discussion of the results and share our conclusions.

\section{Data collection}

Building a database that more or less reflects Turkish Maqam music practice is essential in order to evaluate how well different suggested theoretical models represent the genre. Which recordings, from which period of time, based on which forms, and performed by which instruments should be included in the database is open to debate. Unfortunately, we could not find in the literature a work that could guide us toward gathering a list of criteria for the construction of such a database. Aside from our own effort described in Bozkurt et al. (2008), we could not find any publicly available databases either.

As is the case with most traditional musics in the world, masters are considered the leading sources of information for Turkish Maqam music. Therefore, we decided to choose recordings only from musicians referred to as 'indisputable masters' in the literature. Aside from the signal-based criteria explained below, no further criteria are applied to the construction of the database, since it is already difficult enough to gather a large collection of monophonic recordings in certain maqams from these musicians.

While we consign to the fact that a different database or additional recordings could yield notably different results than those reached in this study, we are confidently assuming that they would not utterly contradict the homogeneity expected of a traditional Maqam music performance, and therefore, ought not devastate our conclusions.

In our database, we included recordings from the following virtuosos: Tanburi Cemil (tanbur, kemençe, violoncello), Mesut Cemil (tanbur, violoncello), Ercü- ment Batanay (tanbur), Fahrettin Çimenli (tanbur), Udi Hrant (violin), Yorgo Bacanos (ud), Aka Gündüz Kutbay (ney), Kani Karaca (vocal), Bekir Sıdkı Sezgin (vocal), Necdet Yaşar (tanbur), İhsan Özgen (kemençe), Niyazi Sayın (ney).

The earliest recordings are those of Tanburi Cemil dated 1910-1914, and the most recent are those of Niyazi Sayın dated 2001 (Sada: Niyazi Sayın. Mega Müzikİstanbul, 2001).

First, a large set of recordings was collected from these musicians. All recordings chosen were monophonic to avoid the complex multi-pitch estimation problem. Pitch/ fundamental frequency (f0) analysis was performed as explained in the next section. To check the accuracy of f0 analysis, stereo audio files were created which contain the original recording in one channel and the re-synthesized sinusoidal signal from estimated $\mathrm{f} 0$ in the other. To filter recordings where f0 estimation errors were relatively high, stereo audio files were examined through simultaneously listening and observing their narrowband spectrogram. An example is presented in Figure 1, where the upper channel contains the original recording and the lower channel contains the synthetic signal spectrogram.

Some of the recordings were rejected owing to encountered problems such as pitch estimation errors due to the high amount of noise and varying rotational speed of phonographs. In the end, the number of recordings with successful pitch estimation for each maqam were determined to be 17 recordings in maqam Hicaz, 15 recordings in maqam Hüseyni, 13 recordings in maqam Hüzzam, 17 recordings in maqam Kürdilihicazkar, 12 recordings in maqam Nihavend, 16 recordings in maqam Rast, 11 recordings in maqam Saba, 16 recordings in maqam Segah and 11 recordings in maqam Uş̧ak.

All of these are among the most popular maqams used in the last century. Maqams pertaining to less than 10

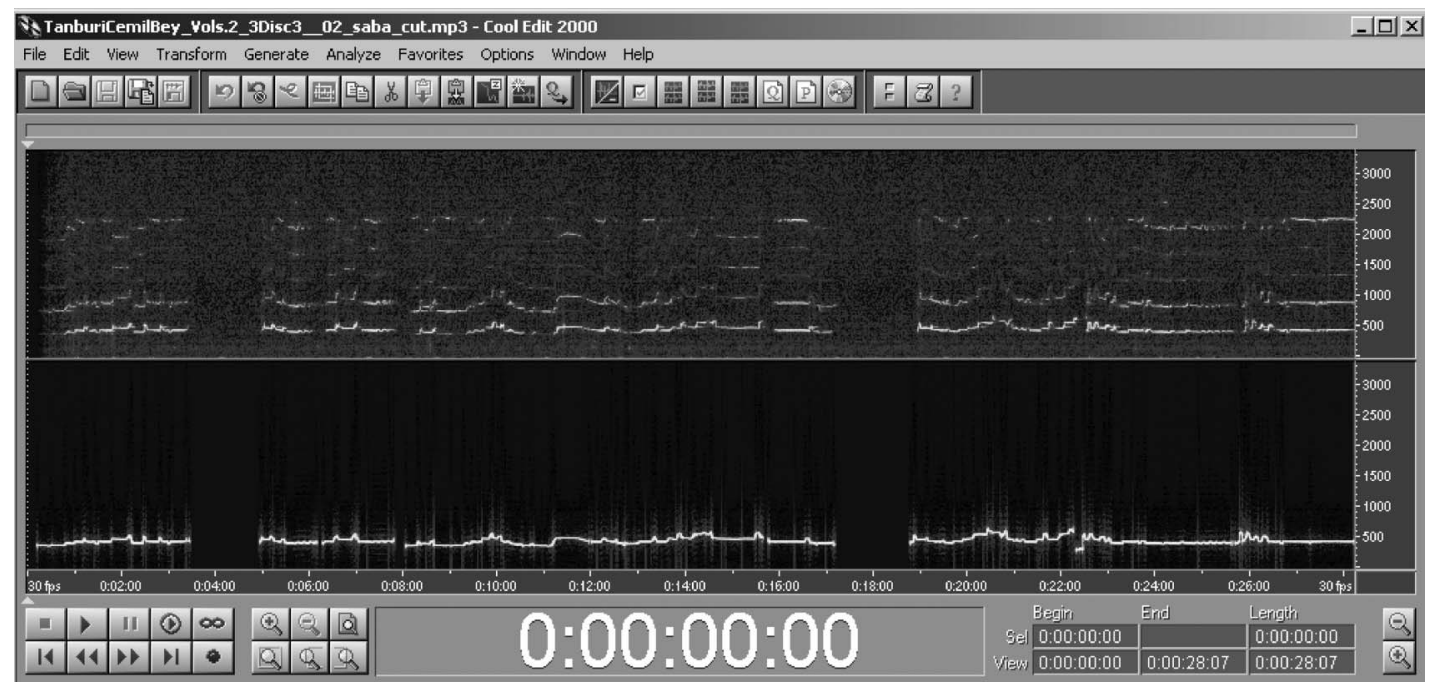

Fig. 1. An example stereo file created for checking the quality of f0 analysis. 
recordings were dropped from the list of maqams to be studied.

\section{The frequency analysis method}

We present below a brief description of the frequency analysis method illustrated in detail in Bozkurt (2008). With the additional peak detection operation, we achieve a completely automatic analysis system that accepts recordings in a given maqam as input and derives an optimum set of relative pitches, hence, a scale for that maqam. Overall frequency analysis procedure for a given maqam category is shown in Figure 2.

\subsection{Fundamental frequency (f0) estimation}

The well-known YIN algorithm (de Cheveigne \& Kawahara, 2002) is used for f0 estimation together with

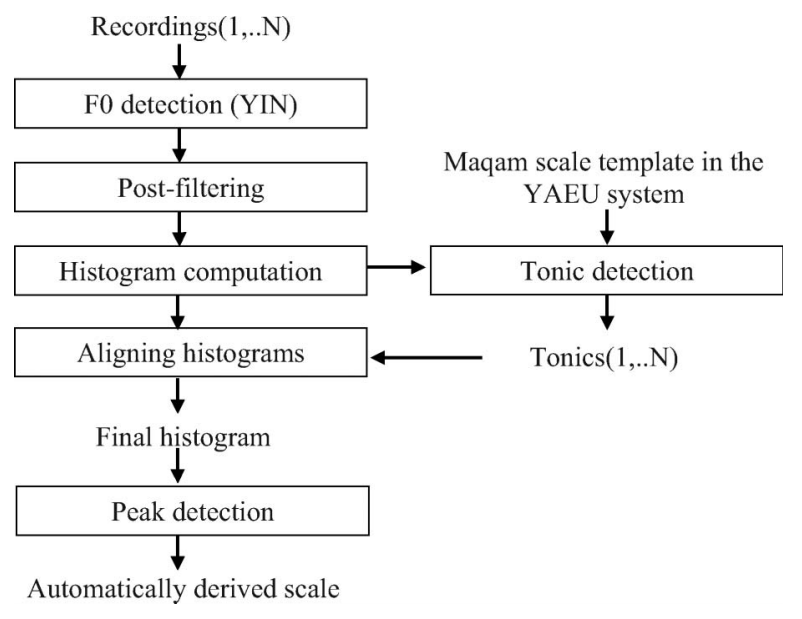

Fig. 2. The overall frequency analysis procedure for a given maqam category. some post-filters designed specifically for Turkish $M a$ qam music as described in Bozkurt (2008). An f0 value is estimated for each $10 \mathrm{~ms}$ period by YIN and special postfilters are applied to correct some of the errors of YIN such as octave doubling/halving and noise.

One way of studying the fo variations is to scrutinize the temporal dynamics of a given recording within the tone grid of a theoretical model as shown in Figure 3.

However, this approach is not very practical for studying mismatches between multiple files and various tunings. The use of histograms for comparison of relative pitches with the tones of suggested maqam scales is more practical and common for such investigations (Akkoç, 2002; Karaosmanoğlu \& Akkoç, 2003; Zeren, 2003; Karaosmanoğlu, 2004). We also use this approach in our study.

The drawback of using histograms instead of timevarying f0 data for analysis of a tuning is the loss of the temporal dimension and therefore, the musical context of executed intervals. However, as detailed comprehensively in the introduction section to this article, our concern is solely the evaluation of the success of proposed theoretical models in representing the maqam scale(s) derived from pitch measurements.

\subsection{Histogram computation}

A pitch histogram, $H f_{0}[n]$, is a mapping that corresponds to the number of $\mathrm{f} 0$ values that fall into various disjoint categories (known as bins):

$$
\begin{aligned}
& H f_{0}[n]=\sum_{k=1}^{K} m_{k}, \\
& m_{k}=1, f_{n} \leq f_{0}[k]<f_{n+1}, \\
& m_{k}=0, \quad \text { otherwise, }
\end{aligned}
$$

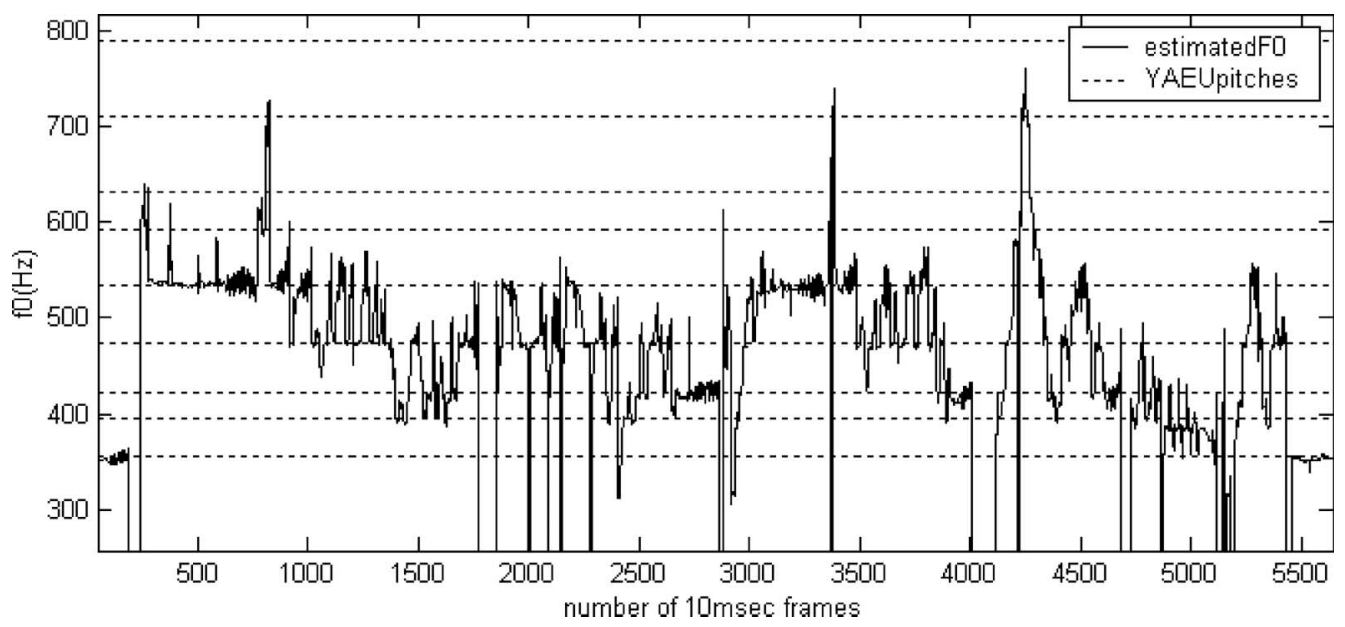

Fig. 3. F0 data in a recording of Tanburi Cemil Bey (Vol 1, Track 2- 'Çeçen kızı' (maqam Hüseyni) plotted together with YAEU tone grid represented as dashed lines. 
where $\left(f_{n}, f_{n+1}\right)$ are boundary values defining the $\mathrm{f} 0$ range for the $n$th bin.

The choice of the bin-width $\left(f_{n+1}-f_{n}\right)$, the width of each category, defines the resolution of the histogram. In studies of theoretical models, it is common practice to use uniform sampling of the whole f0 range.

One of the critical choices made in histogram computation is the decision of bin-width where automatic methods are concerned. In automatic processing of histograms, peak detection is one of the basic operations; therefore the detection of note peaks should be of prime concern. A fine grid, i.e. small bin-width, has an advantage in terms of precision but is disadvantageous for automatic peak picking since spurious peaks are produced. The situation is the other way around for a coarse grid, i.e. large bin-width where some peaks are lost. As a result of empirical tests with various grid sizes, we decided to use the $1 / 3$ Holderian comma $^{19}$ (Hc) resolution, a value that optimizes smoothness and precision of pitch histograms. Moreover, this resolution is the highest master tuning scheme we could find from which a subset tuning is derived for Maqam music (as specified in Yarman, 2008). In all the pitch histograms used in this study, the data is measured with $1 / 3 \mathrm{Hc}$ precision with respect to the tonic. A higher precision of $1 / 12 \mathrm{Hc}$ is used for rounding the relative pitch values of the five theoretical models in order to avoid too rough a quantization, which yields only one cent maximum absolute error for any given tone of any tuning discussed in this article. For the sake of combining both frequency measurements and maqam scales on the same plots, upsampling by a factor of 4 is applied to pitch histograms produced in Section 4.

\subsection{Tonic detection and histogram alignment}

In the analysis of large databases for Turkish Maqam music, the most problematic part is correlating results from multiple files. Due to diapason differences between recordings, lining up the analysed data from various files is impossible without a reference point. Fortunately, the tonic of each maqam serves as a viable reference point. Hence, we utilize an automatic tonic detection algorithm that finds, as an initial step, the highest cross-correlation between a YAEU maqam scale template and the f0 histogram of a given recording. Then the scale template is redrawn from lined up histograms and alignment with all files is re-performed. Using this approach, all histograms are aligned with respect to each other in an iterative manner and the tonics are found. Once the tonics are found, histograms of all files for a given

\footnotetext{
${ }^{19}$ It is common practice to use the Holderian comma $(\mathrm{Hc})$ as the smallest intervallic unit in Turkish Maqam music theoretical parlance. To facilitate comparisons with other models, we also use the Holderian comma unit in our figures and tables.
}

maqam can be collated to compute a final, overall histogram.

The computation of the overall histogram for a given maqam is achieved via two different methods. In the first method, simple averaging is used, i.e. all histograms are summed and finally normalized to obtain an overall histogram. This type of histogram is referred to as 'the average histogram'. In the second method, the maximum function is used, which results in an 'envelope histogram' derived from the superposition of all histograms. Examples are produced in the next section.

\subsection{Automatic peak detection and scale computation}

Once overall histograms are computed, it is straightforward to derive a possible scale by detecting the peaks of the histogram. To achieve robust peak picking, first a 3tap moving average filter is applied to smooth the overall histogram, then the local maxima are detected. Since the lobes are not necessarily symmetric with respect to their local maxima, the center of gravity is computed from 7 data points taken around each local maximum to find a representative peak for each lobe. The peaks obtained from the average histogram and the envelope histogram are labelled in Figures 4 to 12 (Section 4) as Autopeakave. and Autopeak-env.

Given the peak locations and the tonic, it is straightforward to compute relative pitches as the distance from peak locations to the tonic in Hc. As a result, we achieve a completely automatic analysis system that accepts recordings in a given maqam as input and derives an optimum scale for the given maqam.

\subsection{Maximum and average distance between theorized scale tones and measured relative pitches}

For studying mismatches between maqam scales according to said theoretical models and measured data, it is useful to define a quantitative distance measure. Given the relative pitches $I_{a i}$ computed from the data automatically, and the theorized scale tones $I_{t i}$, the maximum distance $M$ and the average distance $D$ between the two values for a given maqam are computed as

$$
\begin{aligned}
M & =\max \left\{\left|I_{a i}-I_{t i}\right|\right\}, \quad i=1,2,3, \ldots, N_{x}, \\
D & =\frac{1}{N_{x}} \sum_{i=1}^{N_{x}}\left|I_{a i}-I_{t i}\right|,
\end{aligned}
$$

where $N_{x}$ is the total number of scale tones for a given maqam that match a measured relative pitch. The number of tones differs for each maqam scale from tuning to tuning and the automatically detected set. For this reason, some of the scale tones need to be excluded in the distance computation. Therefore, only the nearest tones within $2.5 \mathrm{Hc}$ vicinity of the measured relative 
pitches are taken into consideration and the rest are discarded. In other words, the distance measure is computed for a subset of a maqam scale from a given tuning that matches the set of automatically detected relative pitches.

In addition to the distance, we also provide an efficiency measure, $E$, which is the ratio, in percentage, of the number of theorized scale tones within $2.5 \mathrm{Hc}$ vicinity of the measured relative pitches, $N_{x}$, to the number of tones of the maqam scale defined in the tuning, $N_{t}$.

$$
E=\left(N_{x} / N_{t}\right) * 100 .
$$

To portray the complexity of a given scale with respect to its tuning, one last measure is provided: $C$, which is the ratio, normalized to a percentage, of the number of unused scale tones, $N_{z}-N_{x}$, to the total number of tones in the tuning, $N_{z}$.

$$
C=\left(1-N_{x} / N_{z}\right) * 100 .
$$

Note that $M, D, E$ and $C$ are calculated for envelope and average histogram peaks separately.

\section{Automatic analysis results}

In this section, we present the results of the automatic analysis process explained in the previous sections applied to our audio database.

Figures 4 to 12 show the global positioning of five theoretical models with respect to relative pitch measurements through nine maqam categories. Envelope and average histograms have been superimposed to save space. Vertical grids indicate the Holderian comma and equal semi-tone resolutions.

The data used in the histograms are projected to Tables 1 to 9 accompanying the figures. Maximum and average distances from histogram peaks as well as mean efficiency and mean complexity values are also provided therein. Numbers that have been struck through are not included in the computations. Lowest values are in bold.

\section{Discussions: Evaluating theoretical models based on quantitative distance information derived from pitch measurements}

In the previous section we have drawn plots that compared automatic analysis results with maqam scales according to various theoretical models. Before proceeding any further, it has to be stated that automatic analysis is not free of errors; i.e. signal processes involved in the fully automatic analysis are not immaculate. In addition, there are three important points to consider in the design of the tests that can result in significant changes in the values obtained. The first is the method of 'finding the single closest match' in assigning theorized scale tones to autopeak values. If this is altered, for instance, by assigning all theoretical values to the same peak within the $2.5 \mathrm{Hc}$ vicinity instead of picking only the closest, the results are drastically affected to the level of twisting the ratings. Through trial and error, we have decided that the method of 'finding the closest match' is more preferable in treating examined theoretical models more fairly. The second factor is the $2.5 \mathrm{Hc}$ tolerance applied. Lowering the threshold to $1.5 \mathrm{Hc}$ would change values in 6 rows, to $1 \mathrm{Hc}, 23$ rows, out of the 45 rows (nine maqam categories, five theoretical models) in total. Again, we have determined that the 2.5 $\mathrm{Hc}$ threshold is agreeable for most situations. The third important factor is the database itself. The addition of even a single recording has the potential to alter the envelope histogram template of a maqam and add a peak or alter the location of a peak. The risk is much lower for average histogram templates. Nevertheless, Turkish maqam tradition is relatively homogeneous so we can trust the addition of new recordings will not grossly distort our findings. All in all, distances calculated in the previous section should be treated not as exact measures, but as decent estimates.

The proposed methodology is the first attempt to computationally measure the theory-practice differences via fully automatic analysis of large databases, and is naturally open to further discussions and improvements. To facilitate such developments and data doublechecking, we share our Matlab tools and database at: ftp://ftp.iyte.edu.tr/share/ktm-nota/TuningMeasure ment.html.

It must also be mentioned in all fairness, that the second author has had the benefit of cross-checking his maqam scales with the autopeak values in Figures 4 to 12, which lends Yarman24 an edge against other theories discussed here in terms of tone selection. Nevertheless, Yarman24 scales contrasted with frequency measurements were based foremost of all on a priori predictions by the second author regarding which tones a maqam should employ. We feel the need to emphasize the fact that Yarman24 was not designed to conform to histogram peaks, but is an altogether separate tuning and theory endeavour (Yarman, 2009).

Let us now start evaluating how the examined theoretical models perform given pitch measurements in nine maqam categories acquired from master Turkish executants.

The first maqam category is Rast, which is based on the superposition of 16 recordings in this maqam. All theoretical models are more or less in agreement on the scale of Rast. Only Mus2 presents two additional tones at 26 and 36 commas which are obviously alterations or modulations to other maqams.

The third AutoPeak-ave. is misleading, since the prominent peak appears to be higher than 16.64 commas. 


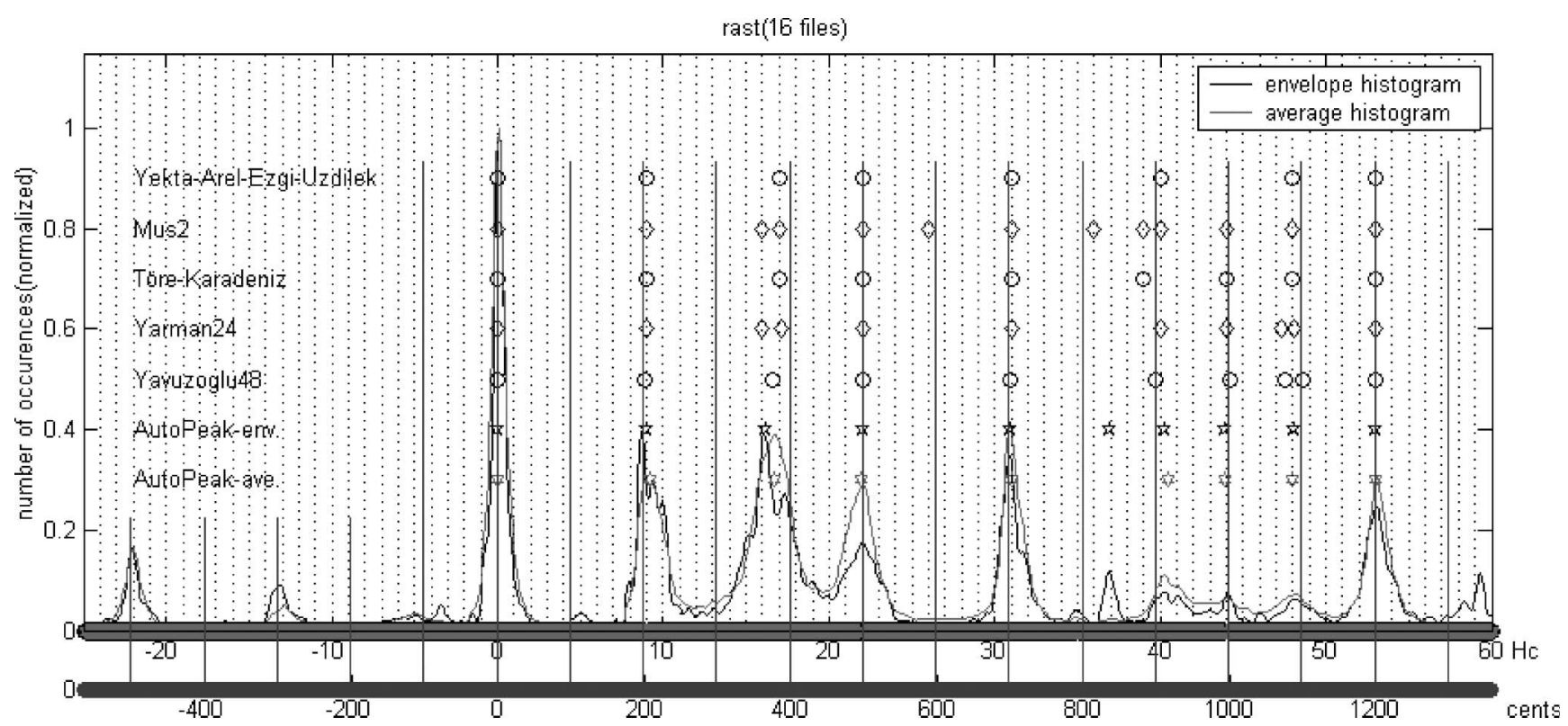

Fig. 4. Histogram computed for maqam Rast comparing autopeaks with theorized scales.

Table 1. Data used in histogram for Figure 4 and quantitative comparison of theorized scales with measured relative pitches. $M_{\mathrm{e}}, D_{\mathrm{e}}$ : maximum and average distance values computed with respect to AutoPeak-env. $M_{\mathrm{a}}, D_{\mathrm{a}}$ : maximum and average distance values computed with respect to AutoPeak-ave. $E, C$ : mean efficiency and mean complexity in percentage.

\begin{tabular}{|c|c|c|c|c|c|c|c|c|c|c|c|c|c|c|c|c|c|}
\hline \multirow{2}{*}{$\begin{array}{l}\text { Rast } \\
\text { YAEU }\end{array}$} & \multicolumn{11}{|c|}{ Distance to tonic in Holderian commas } & \multirow{2}{*}{$\begin{array}{l}M_{\mathrm{e}} \\
0.85\end{array}$} & \multirow{2}{*}{$\begin{array}{r}D_{\mathrm{e}} \\
0.23\end{array}$} & \multirow{2}{*}{$\frac{M_{\mathrm{a}}}{0.4}$} & \multirow{2}{*}{$\begin{array}{c}D_{\mathrm{a}} \\
0.18\end{array}$} & \multirow{2}{*}{$\begin{array}{r}E \\
100\end{array}$} & \multirow{2}{*}{$\begin{array}{r}C \\
75\end{array}$} \\
\hline & 9.01 & & 16.98 & 22 & 31 & & & 40.01 & & & 47.98 & & & & & & \\
\hline Mus2 & 9 & 16 & 17 & 22 & 31 & 36 & 39 & 40 & 44 & & 48 & 0.93 & 0.2 & 0.41 & 0.17 & 68.2 & 85.8 \\
\hline TK & 9 & & 17 & 22 & 31 & & & 39 & 44 & & 48 & 1.24 & 0.35 & 1.41 & 0.31 & 100 & 82.9 \\
\hline Yarman24 & 9.01 & 15.88 & 17.06 & 22 & 31 & & & 40.01 & 43.99 & 47.33 & 48.07 & 0.26 & 0.11 & 0.42 & 0.18 & 77.8 & 70.8 \\
\hline Yavuzoglu48 & 8.83 & & 16.56 & 22.08 & 30. & & & 39.75 & 44.17 & 47.48 & 48.58 & 0.49 & 0.27 & 0.66 & 0.31 & 87.5 & 85.4 \\
\hline AutoPeak-env. & 9 & 16.1 & 13 & 21.99 & 30. & 36.9 & & 40.24 & 43.94 & & 48.12 & & & & & & \\
\hline AutoPeak-ave. & 9.17 & & 16.64 & 21.9 & 31. & & & 40.41 & 43.91 & 48 & .01 & & & & & & \\
\hline Rast & & & & & Dis & tance to & tonic $\mathrm{i}$ & n cents & & & & & & $M_{\mathrm{e}}$ & $D_{\mathrm{e}}$ & $M_{\mathrm{a}}$ & $D_{\mathrm{a}}$ \\
\hline YAEU & 204 & & 384.5 & 498.1 & & 701.9 & & & 905.9 & & & & 86.3 & 19.2 & 25.2 & 9.1 & 4.1 \\
\hline Mus2 & 203.8 & 362.2 & 384.9 & 498.1 & 588.7 & 701.9 & 815.1 & 883.0 & 905.7 & 996.2 & & & 86.8 & 21.0 & 4.5 & 9.3 & 3.8 \\
\hline $\mathrm{TK}$ & 203.8 & & 384.9 & 498.1 & & 701.9 & & & 883.0 & 996.2 & & & 86.8 & 28.1 & 17.9 & 31.9 & 7.0 \\
\hline Yarman24 & 204 & 359.5 & 386.3 & 498.1 & & 701.9 & & & 905.9 & 996 & 1071.6 & 108 & 88.4 & 5.9 & 2.5 & 9.5 & 4.1 \\
\hline Yavuzoglu48 & 200 & & 375 & 500 & & 700 & & & 900 & 1000 & 1075 & 110 & & 11.0 & 6.1 & 14.9 & 7.0 \\
\hline AutoPeak-env. & 203.8 & 365.2 & 497.9 & & 699.2 & 836.2 & & 911.1 & 994.9 & & 1089.5 & & & & & & \\
\hline AutoPeak-ave. & 207.6 & & 376.8 & 495.8 & & 702.3 & & & 914.9 & 994.2 & & 087.0 & & & & & \\
\hline
\end{tabular}

This value is suitable solely as a mean of the two nearby peaks. Only Mus2 and Yarman24 make the distinction between the two peaks at 16 and 17 commas. While Yavuzoğlu48 conforms to the mean value of 16.64 with a 16.56 comma tone, we think it a misrepresentation of the Rast scale. To clarify: the 375 cent major third of Yavuzoğlu48 is a poor approximation of either Just Intonation ratio $16 / 13$ (359 cents, corresponding to the 16 comma peak) or 5/4 (386 cents, corresponding to the 17 comma peak), both of which are present in Yarman24 and finely compensated by Mus2 - whereas YAEU can account for only the latter ratio minus a schisma. ${ }^{20}$

A similar mishap concerns the 48 comma peak, which Yavuzoğlu48 misses by half a comma both to the left and to the right. In contrast, one of the two tones (47.33 and 48.07 commas) in Yarman24 conforms with the peaks.

\footnotetext{
${ }^{20}$ The ratio of a schisma is $32805: 32768$. It is an miniscule interval of 2 cents attained by subtracting 5 octaves from a stack of 8 pure fifths plus 1 pure major third.
} 


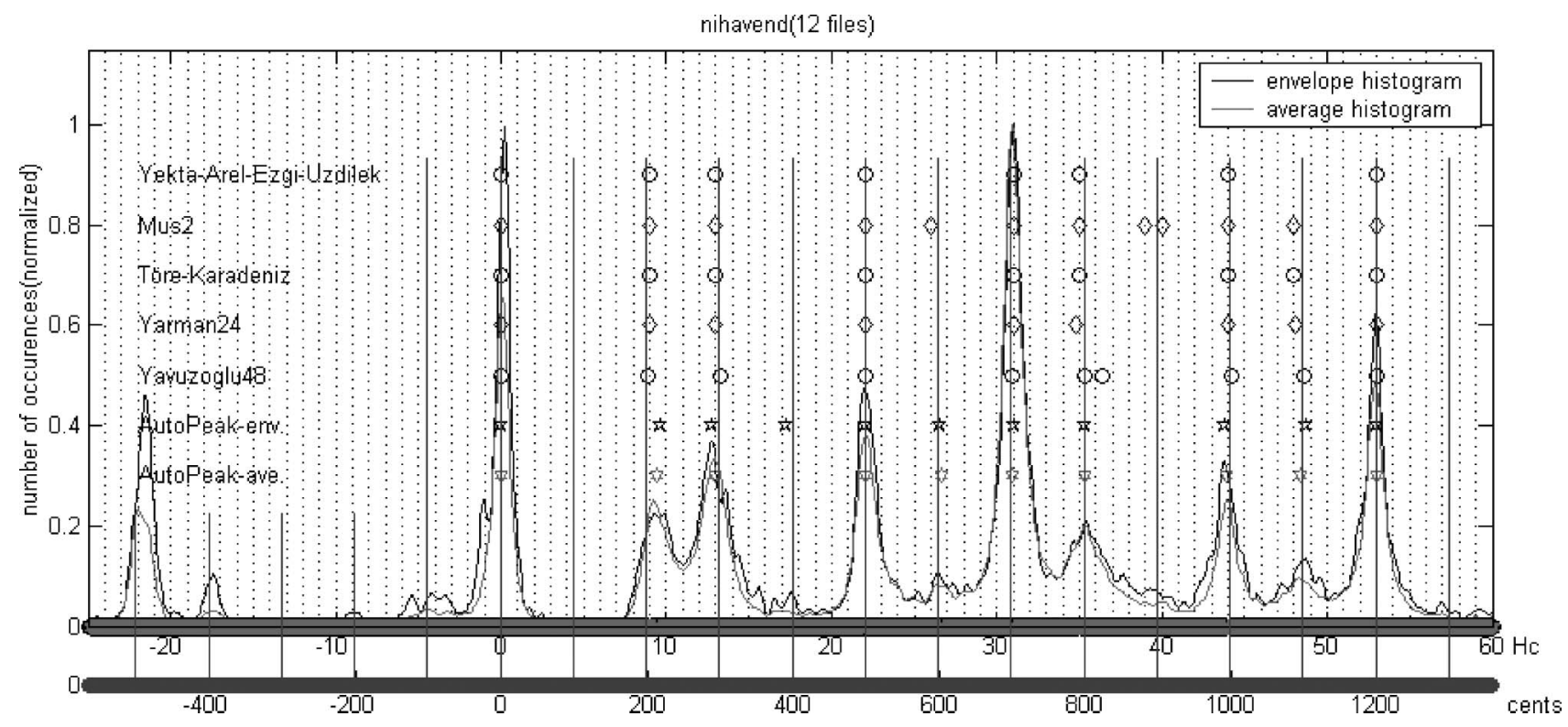

Fig. 5. Histogram computed for maqam Nihavend comparing autopeaks with theorized scales.

Table 2. Data used in histogram for Figure 5 and quantitative comparison of theorized scales with measured relative pitches. $M_{\mathrm{e}}, D_{\mathrm{e}}$ : maximum and average distance values computed with respect to AutoPeak-env. $M_{\mathrm{a}}, D_{\mathrm{a}}$ : maximum and average distance values computed with respect to AutoPeak-ave. $E, C$ : mean efficiency and mean complexity in percentage.

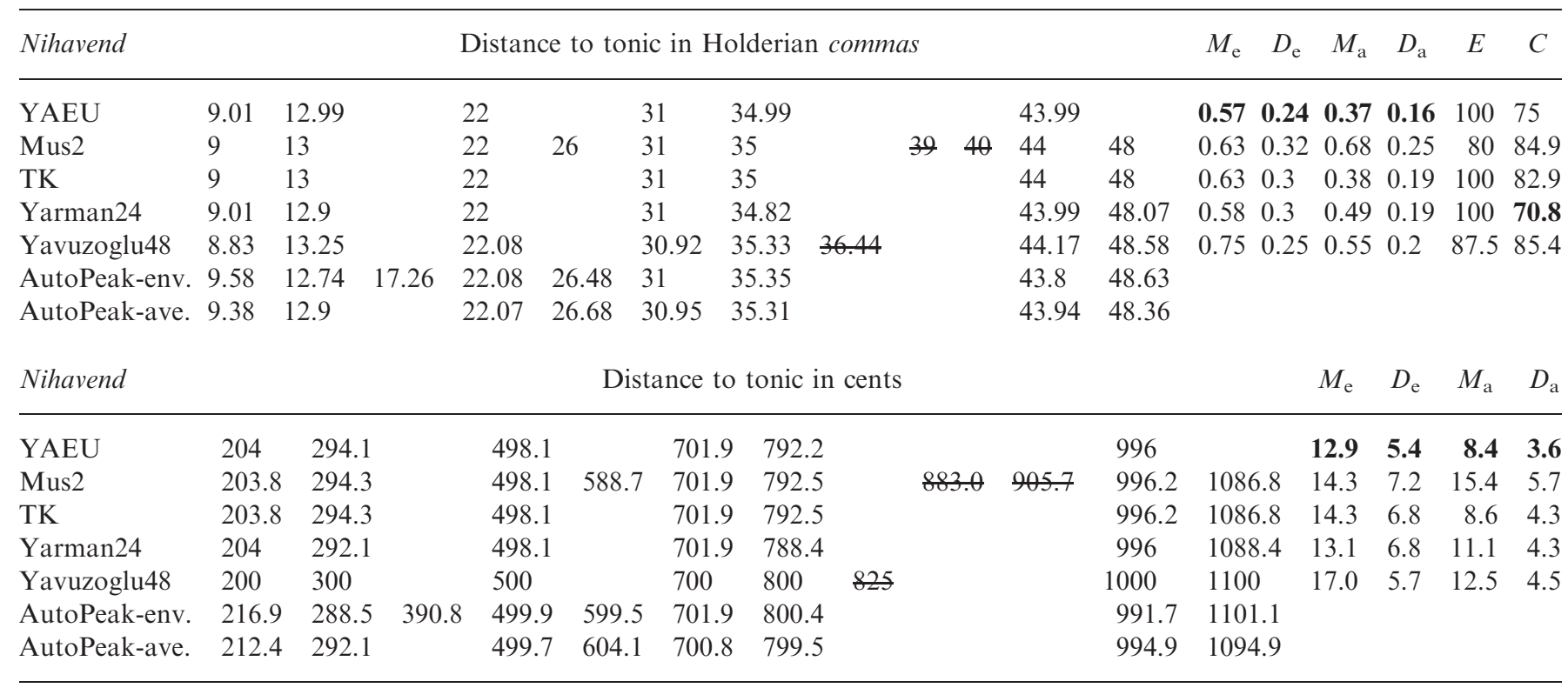

Similarly, Mus2 suggests two tones (39 and 40 commas) in the region of 40 commas one of which conforms with the peaks. TK and Yavuzoğlu48 deviate considerably at this point, where TK yields the worst score.

Mus2's $M$ with respect to AutoPeak-env. is high due to the modulatory tone at 36 commas, which should have been 37 commas that is also available in Mus2's arsenal. Even so, $M$ with respect to Autopeak-ave. is fairly low, signifying closeness of match with performance.

Immediately striking the eye is the lowness of $C$ and overall high level of match with Yarman24. In compar- ison, YAEU lags behind in all but one measure despite the fact that its tuning possesses the same number of tones per octave.

The five theoretical models are ranked according to their average $M$ and $D$ measures in maqam Rast as follows:
1. Yarman24
$M: 0.34, D: 0.15$
2. Yavuzoğlu48
3. YAEU
$M: 0.58, D: 0.29$
4. Mus2
$M: 0.63, D: 0.21$
5. TK
$M: 1.33, D: 0.33$ 


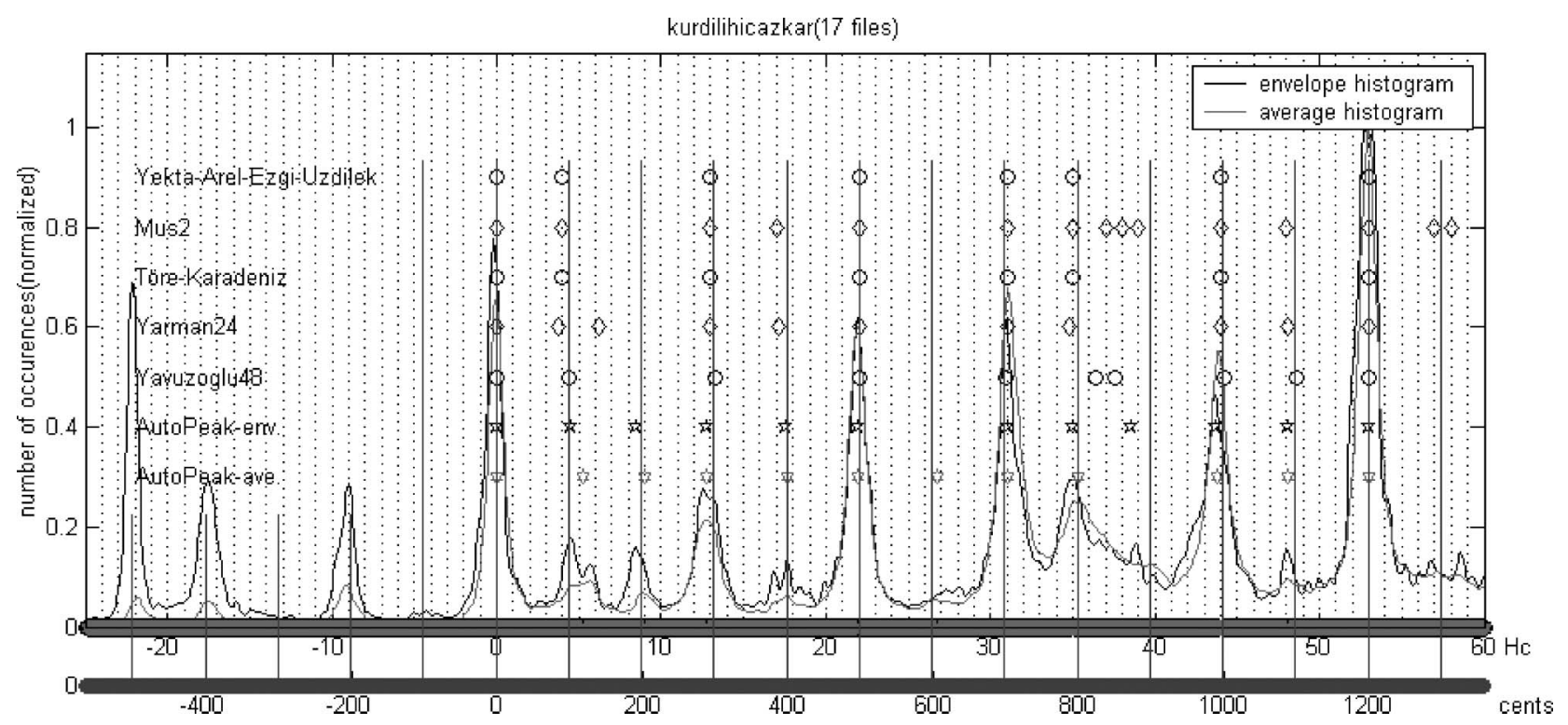

Fig. 6. Histogram computed for maqams Kürdilihicazkar comparing autopeaks with theorized scales.

Table 3. Data used in histogram for Figure 6 and quantitative comparison of theorized scales with measured relative pitches. $M_{\mathrm{e}}, D_{\mathrm{e}}$ : maximum and average distance values computed with respect to AutoPeak-env. $M_{\mathrm{a}}, D_{\mathrm{a}}$ : maximum and average distance values computed with respect to AutoPeak-ave. $E, C$ : mean efficiency and mean complexity in percentage.

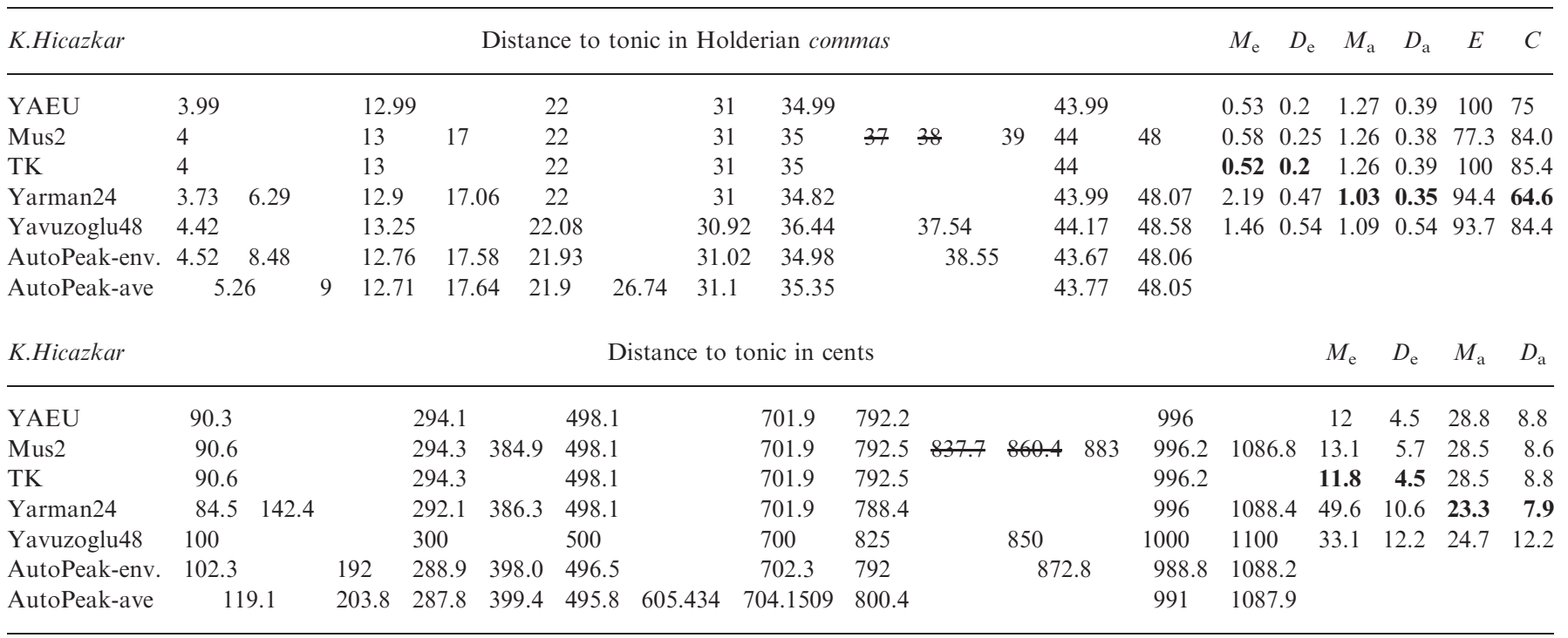

We continue with Nihavend, the data for which is gathered from the superposition of 12 recordings in this maqam. We are satisfied to observe that AutoPeak-env. and AutoPeak-ave. values are very much in accord except for the 17.26 comma peak. This and the 26.5 comma peaks are very likely alterations or modulatory tones. Mus2 matches the latter peaks with a 26 comma tone and produces two more tones at 39 and 40 commas that have no corresponding peaks and seem out of place. Aside from these, all the theoretical models are in agreement as to the scale of Nihavend.

Only Yavuzoğlu48 suggests two proximal tones separated by 25 cents. They occur at 35.33 and 36.44 commas respectively although only the former has been paired with the peaks.

The best tuning for Nihavend is clearly YAEU, with Yarman24 and TK in hot pursuit. We accentuate Yarman24 before TK due to much lower complexity and a lower $M_{\mathrm{e}}$ value. Mus2 scores the worst for this 


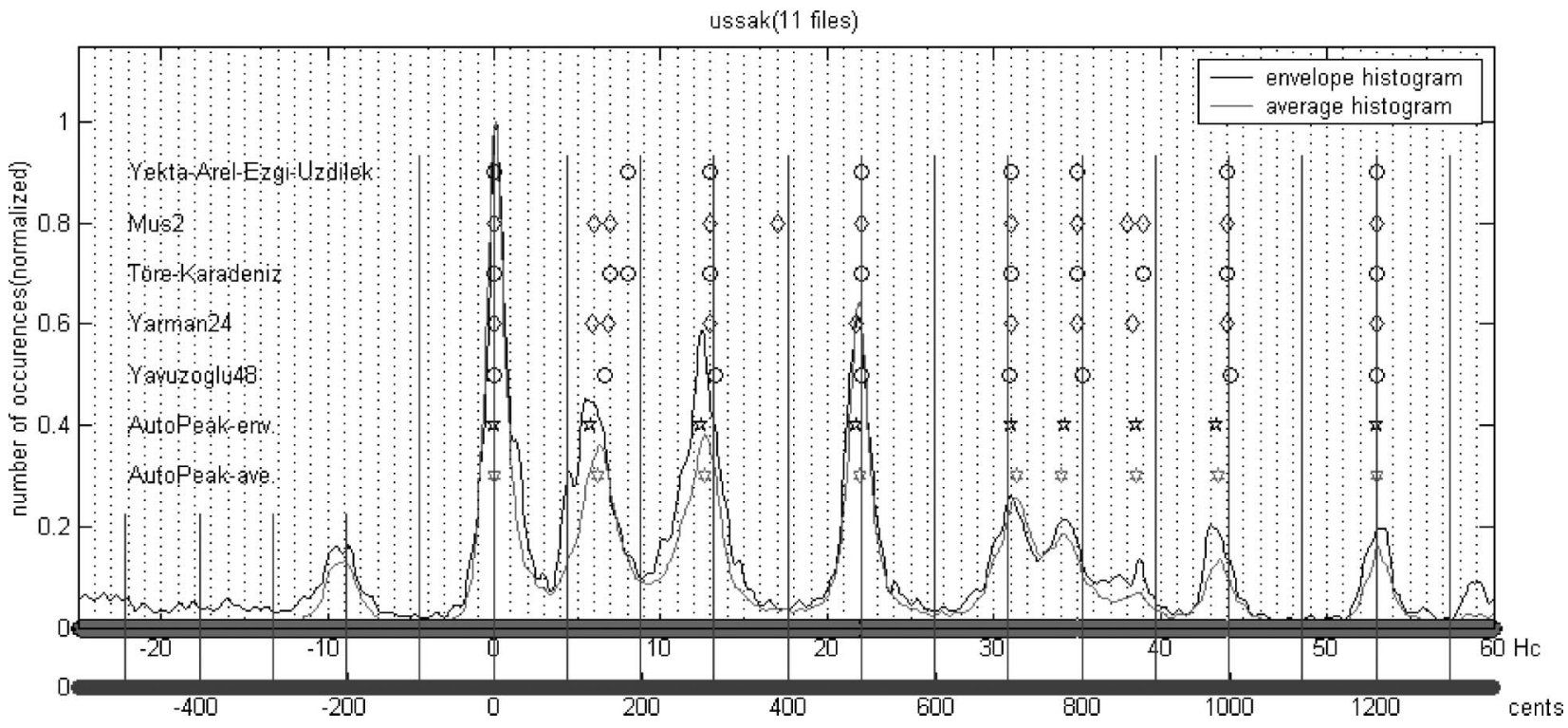

Fig. 7. Histogram computed for maqam Uş̧̧ak comparing autopeaks with theorized scales.

Table 4. Data used in histogram for Figure 7 and quantitative comparison of theorized scales with measured relative pitches. $M_{\mathrm{e}}, D_{\mathrm{e}}$ : maximum and average distance values computed with respect to AutoPeak-env. $M_{\mathrm{a}}, D_{\mathrm{a}}$ : maximum and average distance values computed with respect to AutoPeak-ave. E, $C$ : mean efficiency and mean complexity in percentage.

\begin{tabular}{|c|c|c|c|c|c|c|c|c|c|c|c|c|c|c|c|c|}
\hline \multirow{2}{*}{$\begin{array}{l}U_{s, s a k} \\
\text { YAEU }\end{array}$} & \multicolumn{10}{|c|}{ Distance to tonic in Holderian commas } & $M_{\mathrm{e}}$ & $D_{\mathrm{e}}$ & $M_{\mathrm{a}}$ & $D_{\mathrm{a}}$ & $E$ & $C$ \\
\hline & & 7.97 & 12.99 & & 22 & 31 & 34.99 & & & 43.99 & 2.24 & 0.74 & 1.69 & 0.68 & 100 & 75 \\
\hline Mus2 & 6 & 7 & 13 & 17 & 22 & 31 & 35 & 38 & 39 & 44 & 0.74 & 0.43 & 1.01 & 0.45 & 70 & 86.8 \\
\hline TK & 7 & 8 & 13 & & 22 & 31 & 35 & & 39 & 44 & 1.27 & 0.57 & 1.01 & 0.52 & 87.5 & 82.9 \\
\hline Yarman24 & 5.84 & 6.87 & 12.99 & & 21.74 & 31 & 34.99 & 38.33 & & 43.99 & 0.73 & 0.34 & 1 & 0.44 & 87.5 & 70.8 \\
\hline Yavuzoglu48 & 6.63 & & 13.25 & & 22.08 & 30.92 & 35.33 & & & 44.17 & 1.07 & 0.68 & 1.35 & 0.61 & 100 & 87.5 \\
\hline AutoPeak-env. & 5.73 & & 12.41 & & 21.78 & 31.04 & 34.26 & 38.52 & & 43.34 & & & & & & \\
\hline AutoPeak-ave. & 6.28 & & 12.62 & & 21.89 & 31.36 & 33.99 & 38.53 & & 43.43 & & & & & & \\
\hline Usşak & & & & & Dist & ance to & onic in & ents & & & & & $M_{\mathrm{e}}$ & $D_{\mathrm{e}}$ & $M_{\mathrm{a}}$ & $D_{\mathrm{a}}$ \\
\hline YAEU & & 180 & & 94.1 & & 498.1 & 701.9 & 792.2 & & & & 996 & 50.7 & 16.8 & 38.3 & 15.4 \\
\hline Mus2 & 135.8 & 158 & & 94.3 & 384.9 & 498.1 & 701.9 & 792.5 & & 60.4 & 883 & 996.2 & 16.8 & 9.7 & 22.9 & 10.2 \\
\hline $\mathrm{TK}$ & 158.5 & 181 & & 94.3 & & 498.1 & 701.9 & 792.5 & & & 883 & 996.2 & 28.8 & 12.9 & 22.9 & 11.8 \\
\hline Yarman24 & 132.2 & 155 & & 94.1 & & 492.2 & 701.9 & 792.2 & & 67.8 & & 996 & 16.5 & 7.7 & 22.6 & 10 \\
\hline Yavuzoglu48 & 150 & & & 00 & & 500 & 700 & 799.9 & & & & 1000 & 24.2 & 15.4 & 30.6 & 13.8 \\
\hline AutoPeak-env. & & 29.7 & & 81 & & 493.1 & 702.8 & 775.7 & & 872.2 & & 981.2 & & & & \\
\hline AutoPeak-ave. & & 42.2 & & 85.7 & & 495.6 & 710.0 & 769.6 & & 872.4 & & 983.3 & & & & \\
\hline
\end{tabular}

maqam despite sharing common tones with YAEU. This is apparently due to the inclusion of modulatory tones.

This is an instance where automatic analysis fails to faithfully represent the actual situation. In truth, highest $M$ values for the core scale of Nihavend belong to Yavuzoğlu48, signifying the greatest amount of mismatch. Nevertheless, we proceed in the same fashion as with Rast, and rank the five theoretical models according to their average $M$ and $D$ measures:
1. YAEU
$M: 0.47, D: 0.20$
2. TK
$M: 0.51, D: 0.25$
3. Yarman24
$M: 0.54, D: 0.25$
4. Yavuzoğlu48
$M: 0.65, D: 0.23$
5. Mus2
$M: 0.66, D: 0.29$

Now comes Kürdilihicazkar with 17 recordings superposed. This is a problematic maqam due to being a composite of Nihavend using the kürdi note and maqam Hicazkar. Immediately noticeable is the high 


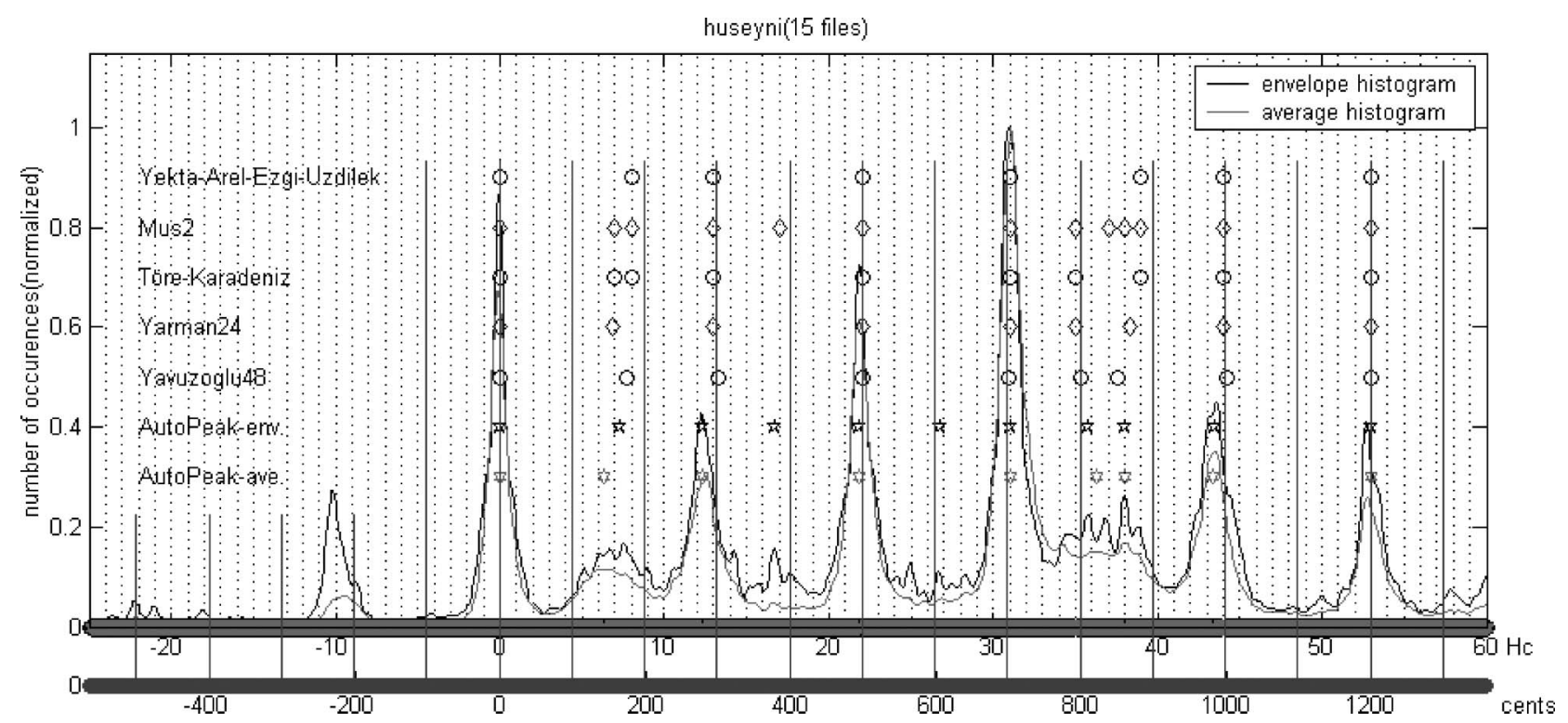

Fig. 8. Histogram computed for maqam Hüseyni comparing autopeaks with theorized scales.

Table 5. Data used in histogram for Figure 8 and quantitative comparison of theorized scales with measured relative pitches. $M_{\mathrm{e}}, D_{e}$ : maximum and average distance values computed with respect to AutoPeak-env. $M_{\mathrm{a}}, D_{\mathrm{a}}$ : maximum and average distance values computed with respect to AutoPeak-ave. $E, C$ : mean efficiency and mean complexity in percentage.

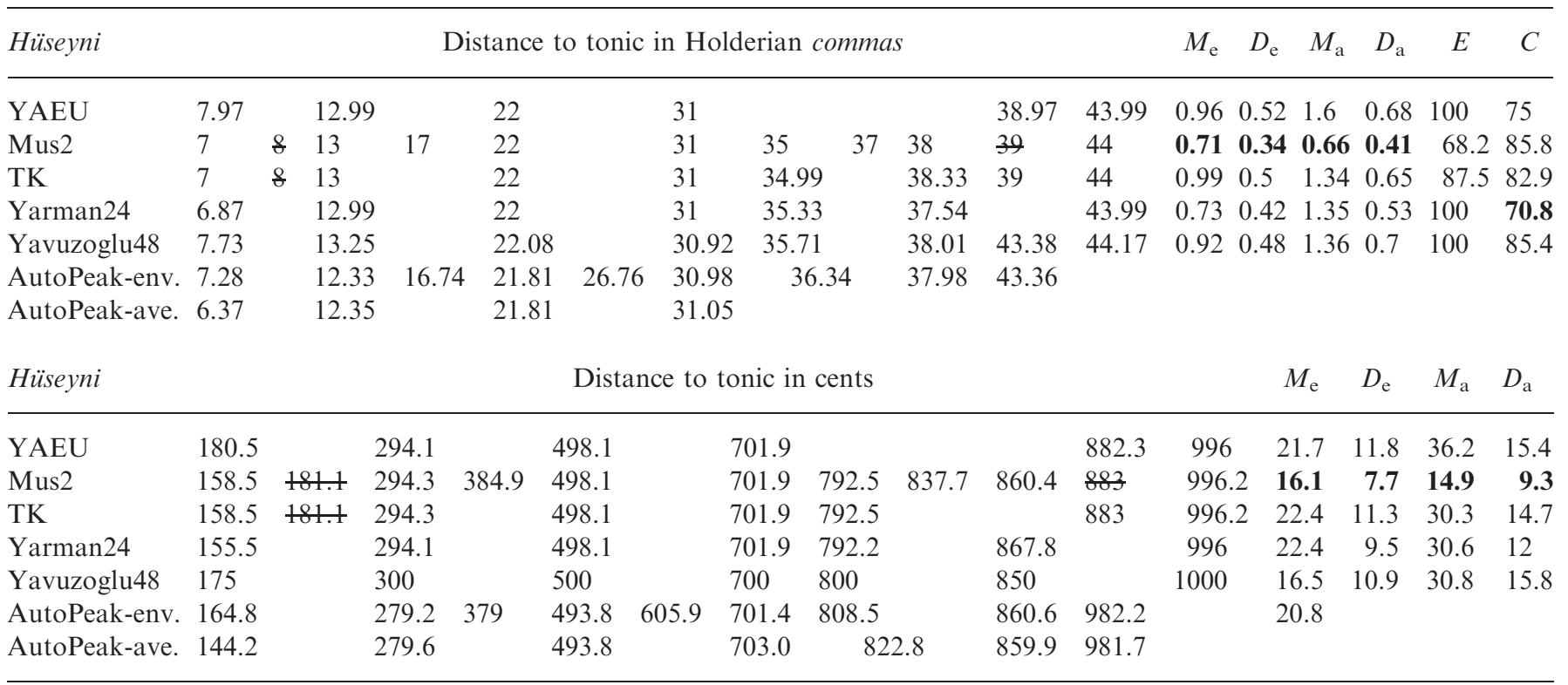

2.19 comma deviation for $M_{\mathrm{e}}$ in Yarman24. Here is another situation where the quantitative distance measures should not be taken at face value. Because the Yarman24 tone of 3.73 commas has been paired with the 4.52 and 5.26 comma autopeaks, the Yarman24 tone of 6.29 commas (much characteristic of Kürdilihicazkar according to the second author) has been paired with the 8.48 comma Autopeak-env. (clearly a modulatory tone) instead of the much closer 5.26 comma peak, whereas Yarman24 boasts a 9.01 comma tone that is much closer to the 8.48 comma AutoPeak-env. which could serve as an alteration but is not given here due to not being part of the core scale of Kürdilihicazkar. A careful scrutiny of the histogram in Figure 6 confirms that there indeed is another peak close to the 6.29 comma tone of Yarman24 that AutoPeak-ave. fails to capture. Instead, AutoPeak-ave. targets the bottom of the valley between the two peaks.

This situation is rectified with $M_{\mathrm{a}}$ and $D_{\mathrm{a}}$ values, where Yarman24 comes out as the best tuning with 


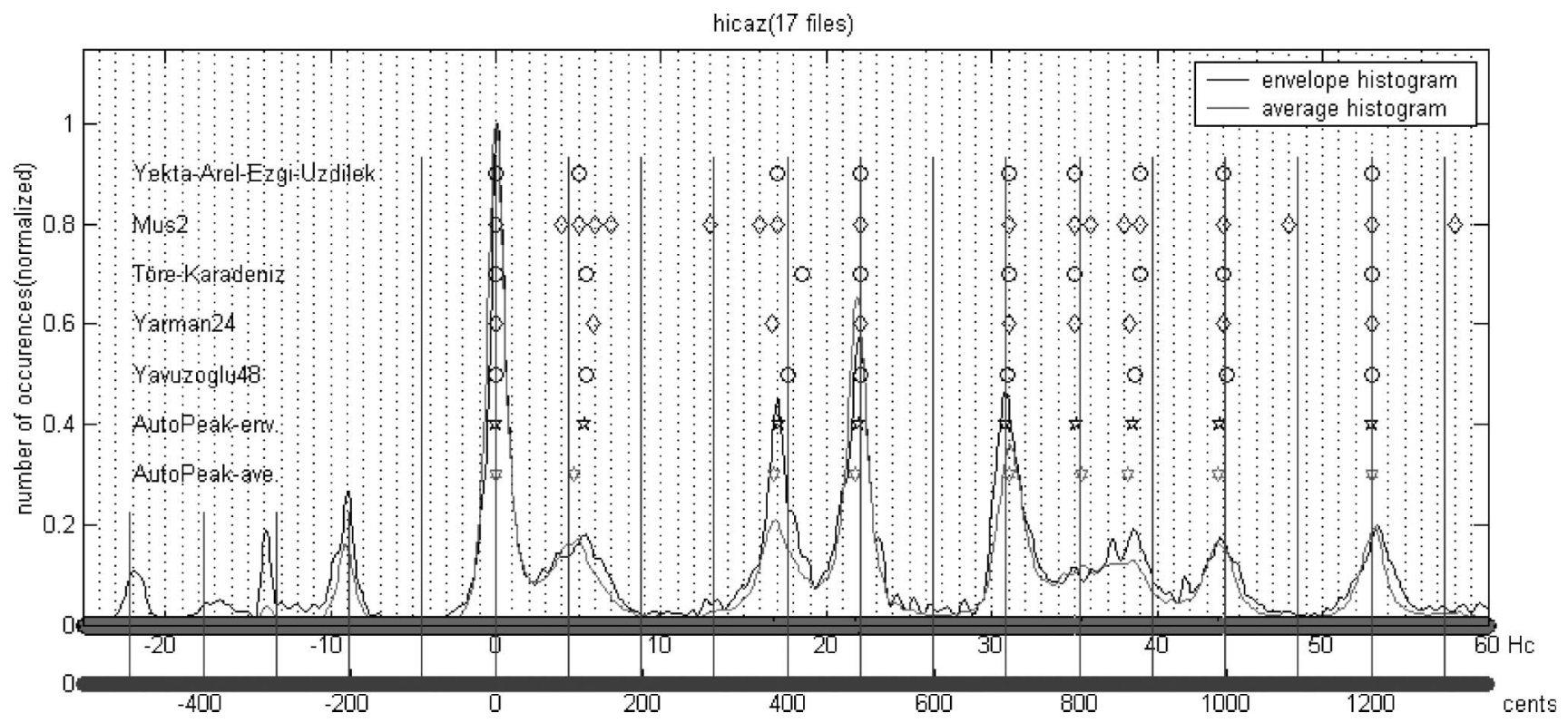

Fig. 9. Histogram computed for maqam Hicaz comparing autopeaks with theorized scales.

Table 6. Data used in histogram for Figure 9 and quantitative comparison of theorized scales with measured relative pitches. $M_{\mathrm{e}}, D_{\mathrm{e}}$ : maximum and average distance values computed with respect to AutoPeak-env. $M_{\mathrm{a}}, D_{\mathrm{a}}$ : maximum and average distance values computed with respect to AutoPeak-ave. $E, C$ : mean efficiency and mean complexity in percentage.

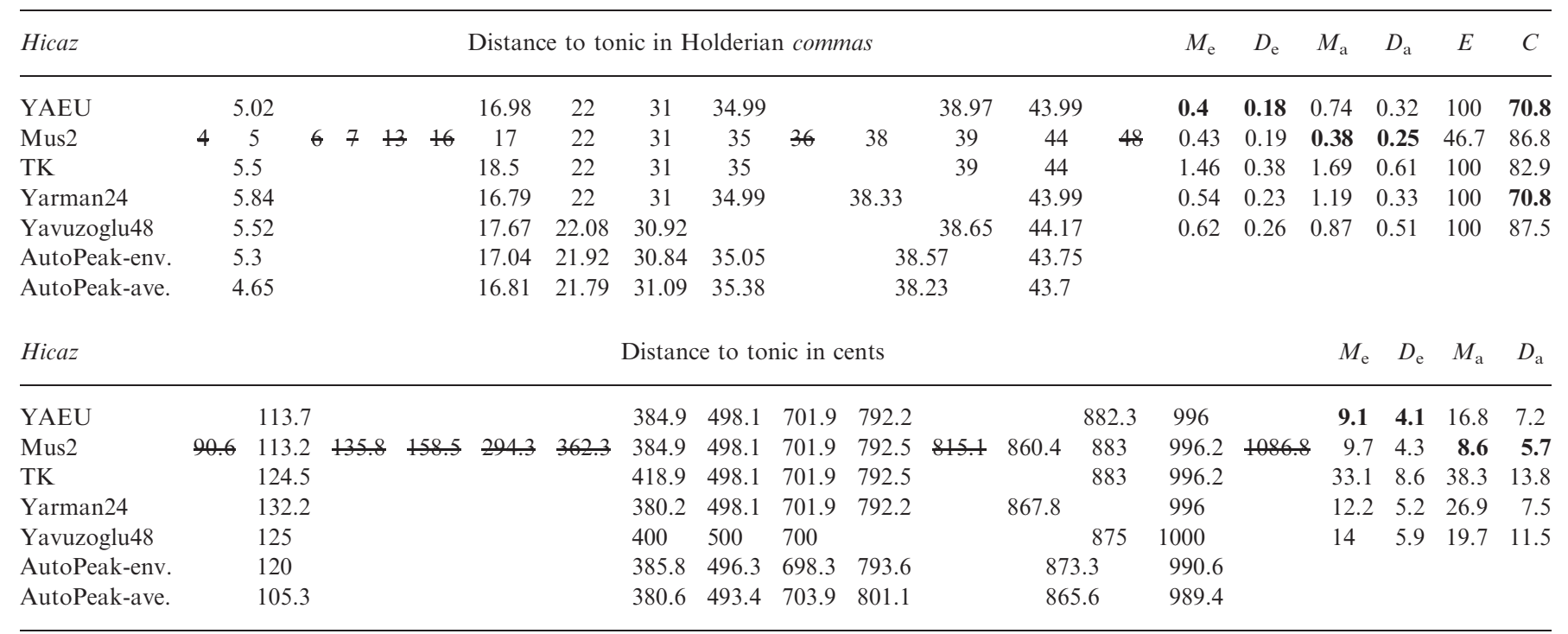

the lowest complexity. Even then, Yarman24's average of $M$ and $D$ values yield the worst results due to taking into account the glitch with the 6.29 comma shade.

In retrospect, Yavuzoğlu48 suggests two proximal tones separated by 25 cents at the 37 comma location that miss the peaks by a long shot and literally fall on the hillside between them. In the meantime, TK, YAEU and Mus2 scores appear homogeneous.
The five theoretical models are ranked according to their average $M$ and $D$ measures in maqam Kürdilihicazkar as follows:
1. TK
$M: 0.89, D: 0.30$
2. YAEU
$M: 0.90, D: 0.30$
3. Mus2
$M: 0.92, D: 0.32$
4. Yavuzoğlu48
$M: 1.28, D: 0.41$
5. Yarman24 


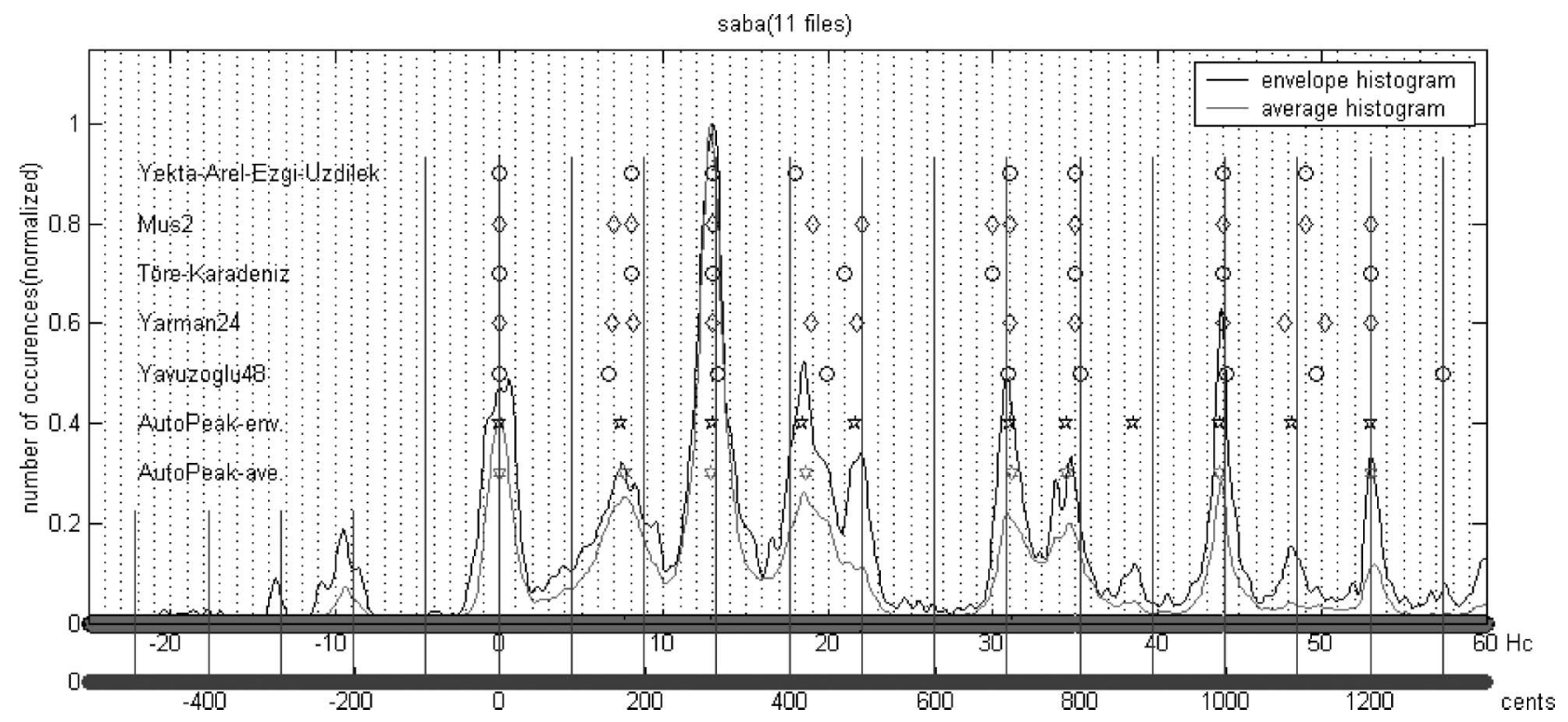

Fig. 10. Histogram computed for maqam Saba comparing autopeaks with theorized scales.

Table 7. Data used in histogram for Figure 10 and quantitative comparison of theorized scales with measured relative pitches. $M_{\mathrm{e}}, D_{\mathrm{e}}$ : maximum and average distance values computed with respect to AutoPeak-env. $M_{\mathrm{a}}, D_{\mathrm{a}}$ : maximum and average distance values computed with respect to AutoPeak-ave. $E, C$ : mean efficiency and mean complexity in percentage.

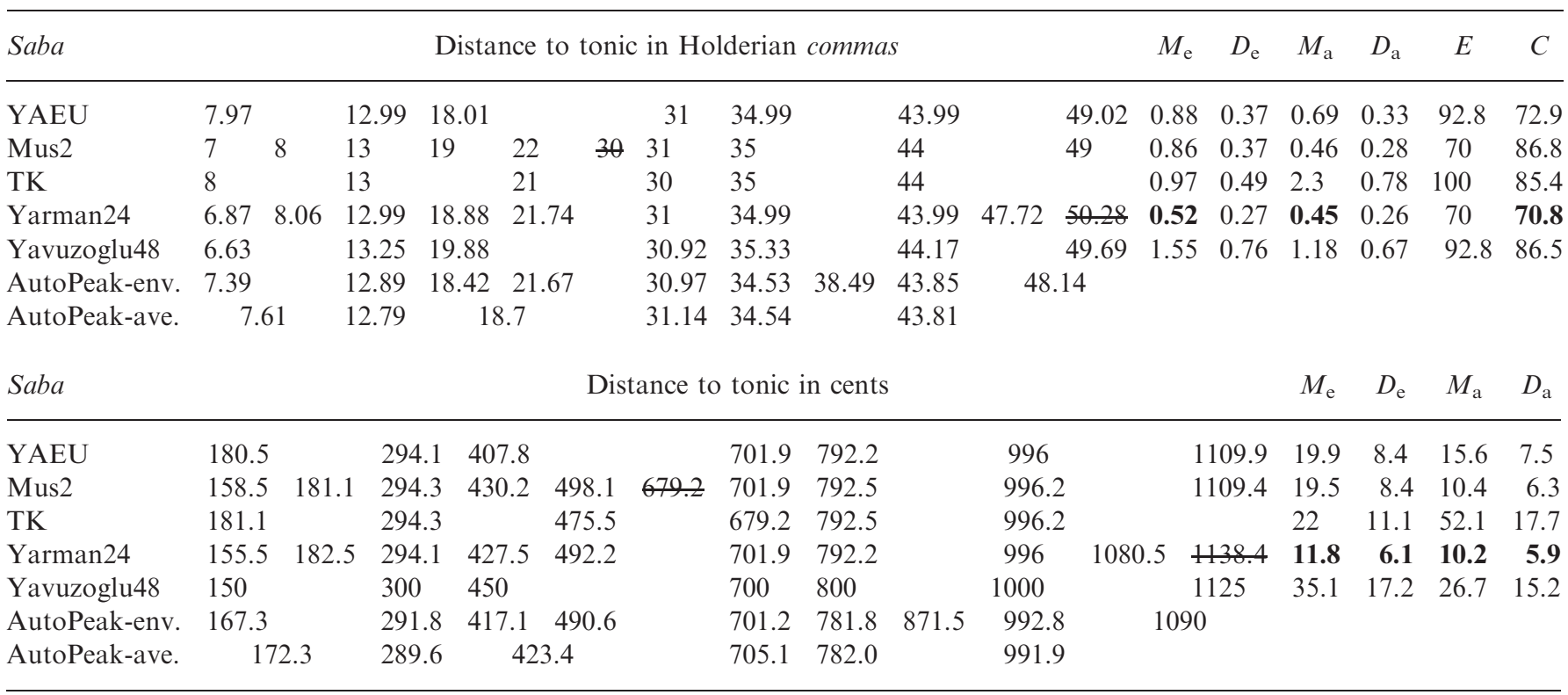

The Uş̧̧ak category is derived from the superposition of 11 recordings. This is a maqam where non-conformance with current theory is the highest. The histogram in Figure 7 shows the awry distribution of suggested scale tones between 6 and 8 commas. Aside from the Mus2 modulatory tone at 17 commas, the scale of Ussak is pretty much uniform for all theoretical models. The crux of Ussak is confirmed to be the 6-8 comma region.
YAEU scores the worst and TK the second worst for misrepresenting this region, whereas TK is in possession of a tone in its tuning that is closer to the peaks but not given as part of the scale. Yavuzoğlu48 suggests at least one tone that brushes the higher peak of said region while grossly missing the 12.5 and 34 comma peaks. On the other hand, Yarman24 and Mus2 are on a par in matching the peaks and perform rather admirably. 


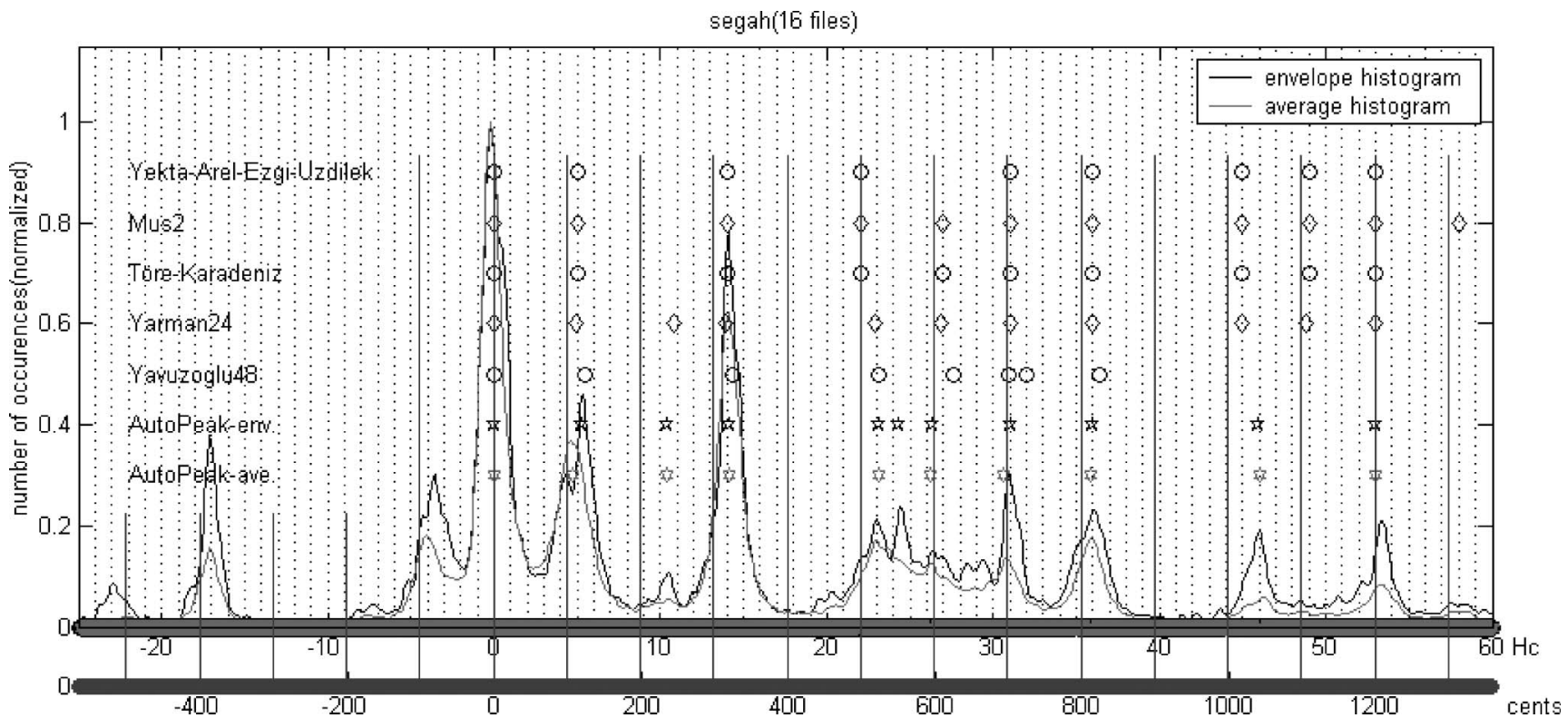

Fig. 11. Histogram computed for maqam Segah comparing autopeaks with theorized scales.

Table 8. Data used in histogram for Figure 11 and quantitative comparison of theorized scales with measured relative pitches. $M_{\mathrm{e}}, D_{\mathrm{e}}$ : maximum and average distance values computed with respect to AutoPeak-env. $M_{\mathrm{a}}, D_{\mathrm{a}}$ : maximum and average distance values computed with respect to AutoPeak-ave. $E, C$ : mean efficiency and mean complexity in percentage.

\begin{tabular}{|c|c|c|c|c|c|c|c|c|c|c|c|c|c|c|c|c|c|}
\hline $\begin{array}{l}\text { Segah } \\
\text { YAEU }\end{array}$ & 5.02 & & 14.03 & 22 & & & 31 & & 36.02 & 45.03 & 49.92 & $\frac{M_{\mathrm{e}}}{1.08}$ & 0.4 & 1.11 & 0.49 & $\begin{array}{c}E \\
85.7\end{array}$ & 75 \\
\hline $\mathrm{TK}$ & 5 & & 14 & 22 & & 27 & 31 & & 36 & 45 & 49 & 1.08 & 0.45 & 1.11 & 0.53 & 87.5 & 82.9 \\
\hline Yarman24 & 4.93 & 10.82 & 13.94 & 22 & 95 & 26.93 & 31 & & 35.9 & 44.94 & 48.84 & 0.96 & 0.34 & 1.06 & 0.4 & 88.9 & 66.7 \\
\hline Yavuzoglu48 & 5.52 & & 14.35 & 23 & 19 & 27.6 & 30.92 & 32.02 & 36.4 & & & 1.29 & 0.42 & 1.34 & 40.55 & 85.7 & 87.5 \\
\hline Segah & & & & & & istance & to tonic & in cents & & & & & $M$ & $I_{\mathrm{e}}$ & $D_{\mathrm{e}}$ & $M_{\mathrm{a}}$ & $D_{\mathrm{a}}$ \\
\hline YAEU & 113.7 & & 317 & & 498.1 & & & 701.9 & & 815.5 & 1019.5 & 1109.9 & 24. & .5 & 9.1 & 25.1 & 11.1 \\
\hline Mus2 & 113.2 & & 317 & & 498.1 & & 611.3 & 701.9 & & 815.1 & 1018.9 & 1109.4 & 24. & .5 & 10.2 & 25.1 & 12 \\
\hline AutoPeak-ave. & 106 & 233.7 & 318 & & 523.2 & & 594.8 & 694.9 & & 812.2 & 1041.7 & & & & & & \\
\hline
\end{tabular}

As a side note, we think the protrusion at 4 commas in Figure 7 definitely indicates a modulation to another maqam.

The five theoretical models are ranked according to their average $M$ and $D$ measures in maqam Ussak as follows:
1. Yarman24
$M: 0.87, D: 0.39$
2. Mus2
$M: 0.88, D: 0.44$
3. TK
$M: 1.14, D: 0.55$

4. Yavuzoğlu48 $M: 1.21, D: 0.65$

5. YAEU $M: 1.97, D: 0.71$

A sibling of Uş̧̧ak is Hüseyni, the data for which have been gathered from the superposition of 15 recordings in this maqam. Although the second note of Hüseyni is not as distinct as the second note of Uş̧ak, the perfect fifth counterpart of this note is just as varied. The crux of Hüseyni appears to be this very region residing between 36-38 commas. 


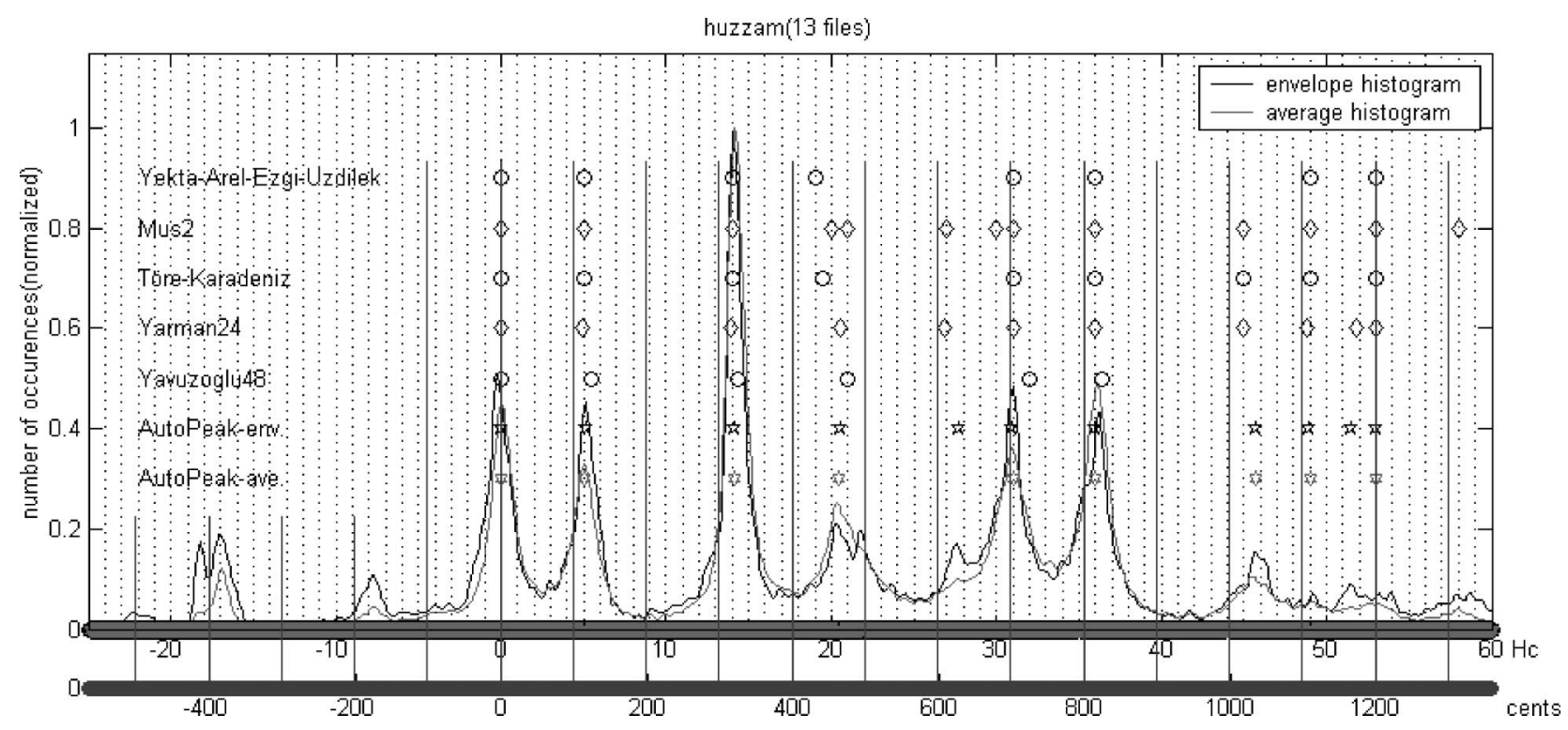

Fig. 12. Histogram computed for maqam Hüzzam comparing autopeaks with theorized scales.

Table 9. Data used in histogram for Figure 12 and quantitative comparison of theorized scales with measured relative pitches. $\mathbf{M}_{\mathrm{e}}$, $\mathrm{D}_{\mathrm{e}}$ : maximum and average distance values computed with respect to AutoPeak-env. $M_{\mathrm{a}}, D_{\mathrm{a}}$ : maximum and average distance values computed with respect to AutoPeak-ave. $E, C$ : mean efficiency and mean complexity in percentage.

\begin{tabular}{|c|c|c|c|c|c|c|c|c|c|c|c|c|c|c|c|c|c|}
\hline \multirow{2}{*}{$\begin{array}{l}\text { Hüzzam } \\
\text { YAEU }\end{array}$} & \multicolumn{11}{|c|}{ Distance to tonic in Holderian commas } & \multirow{2}{*}{$\begin{array}{l}M_{\mathrm{e}} \\
1.42\end{array}$} & \multirow{2}{*}{$\frac{D_{\mathrm{e}}}{0.3}$} & \multirow{2}{*}{$\frac{M_{\mathrm{a}}}{1.4}$} & \multirow{2}{*}{$\frac{D_{\mathrm{a}}}{0.28}$} & \multirow{2}{*}{$\begin{array}{r}E \\
100\end{array}$} & \multirow{2}{*}{$\begin{array}{r}\mathrm{C} \\
75\end{array}$} \\
\hline & 5.02 & 14.03 & 19.05 & & & & 31 & 36.02 & & 49.02 & & & & & & & \\
\hline Mus2 & 5 & 14 & 20 & 24 & 27 & 30 & 31 & 36 & 45 & 49 & & 0.75 & 0.29 & 0.66 & 0.2 & 75 & 85.8 \\
\hline $\mathrm{TK}$ & 5 & 14 & 19.5 & & & & 31 & 36 & 45 & 49 & & 0.97 & 0.3 & 0.95 & 0.27 & 100 & 82.9 \\
\hline Yarman24 & 4.93 & 13.94 & 20.59 & & 26.93 & & 31 & 35.94 & 44.94 & 48.84 & 51.81 & 0.82 & 0.3 & 0.71 & 0.2 & 88.9 & 66.7 \\
\hline Yavuzoglu48 & 5.52 & 14.35 & 20.98 & & & & 32.02 & 36.44 & & & & 1.11 & 0.54 & 1.05 & 0.54 & 100 & 89.6 \\
\hline AutoPeak-env. & 5.11 & 14.12 & 20.47 & & 27.75 & & 30.91 & 35.98 & 45.74 & 48.95 & 51.46 & & & & & & \\
\hline AutoPeak-ave. & 4.99 & 14.17 & 20.45 & & & & 30.97 & 36.03 & 45.66 & 48.98 & & & & & & & \\
\hline
\end{tabular}

\begin{tabular}{|c|c|c|c|c|c|c|c|c|c|c|c|c|c|c|c|}
\hline Hüzzam & & & & & Distan & e to to & ic in $\mathrm{ce}$ & & & & & $M_{\mathrm{e}}$ & $D_{\mathrm{e}}$ & $M_{\mathrm{a}}$ & $D_{\mathrm{a}}$ \\
\hline YAEU & 113.7 & 317.7 & 431.3 & & & & 701.9 & 815.5 & & 1109.9 & & 32.2 & 6.8 & 31.7 & 6.3 \\
\hline Mus2 & 113.2 & 317 & 452.8 & 475.5 & 611.3 & 679.2 & 701.9 & 815.1 & 1018.9 & 1109.4 & & 17 & 6.6 & 14.9 & 4.5 \\
\hline TK & 113.2 & 317 & 441.5 & & & & 701.9 & 815.1 & 1018.9 & 1109.4 & & 22 & 6.8 & 21.5 & 6.1 \\
\hline Yarman24 & 111.6 & 315.6 & 466.2 & & 609.7 & & 701.9 & 813.7 & 1017.5 & 1105.8 & 1173.1 & 18.6 & 6.8 & 16.1 & 4.5 \\
\hline Yavuzoglu48 & 125 & 325 & 475 & & & & 725 & 825 & & & & 25.1 & 12.2 & 23.8 & 12.2 \\
\hline AutoPeak-env. & 115.7 & 319.7 & 463.5 & & 628.3 & & 699.8 & 814.6 & 1035.6 & 1108.3 & 1165.1 & & & & \\
\hline AutoPeak-ave. & 113 & 320.8 & 463.0 & & & & 701.2 & 815.8 & 1033.8 & 1109 & & & & & \\
\hline
\end{tabular}

Mus2 fills this region with virtually every comma step in its arsenal and comes up as the winner. Yarman24 and Yavuzoğlu48 follow the trail of Mus2. YAEU and TK are equal in failing to represent Hüseyni.

The five theoretical models are ranked according to their average $M$ and $D$ measures in maqam Hüseyni as follows:

1. Mus2

2. Yarman24

$M: 0.69, D: 0.38$

$M: 1.04, D: 0.48$
3. Yavuzoğlu48 $M: 1.14, D: 0.59$

4. TK

$M: 1.17, D: 0.58$

5. YAEU

$M: 1.28, D: 0.60$

One of the more popular maqams is next. The data gathered from 17 recordings in maqam Hicaz are shown in Figure 9 and Table 6. Mus2 employs a lot of commas for the scale of this maqam, a great concentration of which are gathered at the second and the sixth notes. Needless to say, Mus2 tones that 
do not correspond to any peaks are doubtlessly alterations or modulations to other maqams. Aside from Mus2, all theoretical models are in full agreement as to the scale of Hicaz.

The histogram in Figure 9 tells us that the second note between 4-7 commas and the sixth note between 35-39 commas are quite fluid. These flexible notes are clearly characteristic of Hicaz. The high concentration of commas by Mus2 in said regions corroborate this observation.

Not surprisingly, Mus2 boasts the best scores, followed by YAEU, Yavuzoğlu48 and Yarman24. The worst scores are that of TK for this maqam due to its suggestion of the wrong tone for the third note despite the existence of a tone closer to the peaks that is 1 Holderian comma lower in its tuning.

The five theoretical models are ranked according to their average $M$ and $D$ measures in maqam Hicaz as follows:

$\begin{array}{lll}\text { 1. } & \text { Mus2 } & M: 0.41, D: 0.22 \\ \text { 2. } & \text { YAEU } & M: 0.57, D: 0.25 \\ \text { 3. } & \text { Yavuzoğlu48 } & M: 0.75, D: 0.39 \\ \text { 4. } & \text { Yarman24 } & M: 0.87, D: 0.28 \\ \text { 5. } & \text { TK } & M: 1.58, D: 0.50\end{array}$

Saba is a very piquant and famous maqam in Traditional Turkish music. Pitch measurements from 11 recordings were superposed for the analysis of Saba. As was the case with Ussak, the second note is a peculiar, albeit less pronounced, feature of this maqam. Yavuzoğlu48 misses the autopeaks here by a comma. TK is in possession of a tone that is closer to AutoPeak-env. but not given here as part of the scale. A more peculiar aspect is the fourth note. Yavuzoğlu48 and TK miss these autopeaks, with the latter falling into a deep ravine, despite possessing tones in their tunings that represent the region better but not given as part of their scales. In contrast, both Mus2 and Yarman24 suggest a pair of tones each for the second and fourth note of Saba in accord with the autopeaks. Also, YAEU seems to represent Saba well even without the commatic inflexions that are considered a requisite of this maqam.

The protrusion at 34 commas in Figure 10 appears to be a commatic inflexion that has no corresponding tone in YAEU and Yarman24. Though Mus2, TK and Yavuzoğlu48 can come up with tones from their tunings that could compensate this protrusion, their inclusion in their proposed scales for $S a b a$ would not affect the scores in the slightest.

The 38.49 and 48.14 comma AutoPeak-env. values most likely signify alterations as part of the Saba maqam. The latter peak is best represented by Yarman24, and worst represented by Yavuzoğlu48.
The five theoretical models are ranked according to their average $M$ and $D$ measures in maqam Saba as follows:

1. Yarman 24

2. Mus2

3. YAEU

$M: 0.49, D: 0.27$

4. Yavuzoğlu48

$M: 0.66, D: 0.33$

$M: 0.79, D: 0.35$

5. TK

$M: 1.37, D: 0.72$

$M: 1.64, D: 0.64$

Segah is a savory and popular maqam. 16 recordings were compiled for the analysis of Segah. Immediately noticeable is the 22-23 comma dichotomy above the tonic. YAEU, Mus2 and TK consider the fourth note a pure fourth above the first, while the latter two theoretical models take an acute fourth above the tonic. We must warn the reader that YAEU, Mus2 and TK all possess tones in their tunings that are exactly 1 comma above the ones they suggest for their scales corresponding to the peak at 23 commas. Therefore, quantitative distance results will probably be misleading for YAEU, Mus2 and TK.

Except for the lack of a 27 comma tone by YAEU and the addition of a 10.82 comma tone by Yarman24 (clearly a modulation to Segah's sister maqam Müstear), all theoretical models agree on the scale of Segah. Only the Yavuzoğlu48 scale is left incomplete and does not reach the octave of the finalis.

We cannot identify the AutoPeak-env. at 24.28 commas and the protrusion at 4 commas with anything significant. This are probably quirks or scordaturas in the execution of the maqam by one or more performers in our database.

The five theoretical models are ranked according to their average $M$ and $D$ measures in maqam Segah. Mus2 and TK distance scores and efficiency results were the same, so complexity was taken into account in ranking them:

$\begin{array}{lll}\text { 1. } & \text { Yarman24 } & M: 1.01, D: 0.37, C: 66.7 \\ \text { 2. } & \text { YAEU } & M: 1.10, D: 0.45, C: 75 \\ \text { 3. } & \text { TK } & M: 1.10, D: 0.49, C: 82.9 \\ \text { 4. } & \text { Mus2 } & M: 1.10, D: 0.49, C: 86.8 \\ \text { 5. } & \text { Yavuzoğlu48 } & M: 1.32, D: 0.49, C: 87.5\end{array}$

A variant of Segah is the sorrowful Hüzzam. 13 recordings in this maqam were compiled for analysis. Theoretical models for Hüzzam appear pretty much uniform, save for the lack of any tone for the 27.75 comma peak except by Mus2 and Yarman24, and the absence of the YAEU counterpart of the 45.7 comma peak as well as the incompleteness of the Yavuzoğlu48 scale just as it was the case with Segah.

The characteristic region of Hüzzam is the zone around 20-22 commas. Unfortunately, the automatic peak detection algorithm missed the 22 comma peak 
which might be just as important and peculiar to Hüzzam as the 20.5 comma peak. However, it is likely a modulation to Segah with a pure fourth above the tonic instead of an acute fourth.

Once more, TK is in possession of a tone in its tuning that represents the above-said zone better although not given as part of the scale of Hüzzam.

The unpronounced octave above the tonic is puzzling. We identify the AutoPeak-env. at 51.46 commas as a scordatura of the octave of the finalis of Hüzzam.

The five theoretical models are ranked according to their average $M$ and $D$ measures in maqam Hüzzam as follows:
1. Mus2
$M: 0.71, D: 0.25$
2. Yarman24
$M: 0.77, D: 0.25$
3. TK
$M: 0.96, D: 0.29$
4. Yavuzoğlu48
$M: 1.08, D: 0.54$
5. YAEU
$M: 1.41, D: 0.29$

\section{Conclusions}

In our weighing of theorized scales against quantitative distance information gathered from pitch histograms, we believe that every one of the five theoretical models listed in this article have been mistreated to some level. That is to say, incorrect peak detections, matching of the measured relative pitches with the wrong scale tones, failure to take into account tones that are already available in a tuning but not included in the theorized scales, and injustice in the calculations arising from the presence of alterations or peripheral modulatory tones occurred at least once for all the competitors. However, considering the variety of recordings (diversity of the recording environment, executants, instruments, etc.), the fact that maqams employ a plethora of intervals, and that the examined theoretical models feature different number of tones within an octave, the consistency obtained in the results are rather high. Although we are of the opinion that TK, Mus2 and Yarman24 were much wronged compared to Yavuzoglu48 and YAEU, it is safe to assume that the scores are quite reliable.

Of course, there is always a risk that the complex microstructure in the temporal sequence of perdes will not be discernable in an overall histogram from multiple recordings - especially when dealing with a musical genre that places such a great emphasis on the tiniest pitch inflexions that also vary from musician to musician. This was most evident in our interpretations of the results in the previous section. However, as we have stressed thoroughly, our priority and focus is the extracting of maqam scale information from overall histograms for comparison with theorized maqam scales. How these scales are employed and how the tones should be bent in a musical context is of secondary importance to us at this juncture.

We deem it significant that the $M, D, E$ and $C$ values are averaged for all theoretical models through all maqam categories for a global assessment. In Table 10, the mean of all maximum and average distance data from histogram autopeaks as well as the grand average of all mean efficiency and mean complexity values have been calculated. From the mean of $M_{\mathrm{em}}, D_{\mathrm{em}}$ and $M_{\mathrm{am}}, D_{\mathrm{am}}$, we have derived $M_{\mathrm{m}}, D_{\mathrm{m}}$. Finally, we have scaled these with $C_{\mathrm{m}}$ to obtain $M_{\mathrm{c}}$ and $D_{\mathrm{c}}$. These last two values

Table 10. Average of M, D, E and C values through nine maqam categories for all theoretical models. $M_{\mathrm{em}}, D_{\mathrm{em}}$ : Mean of all maximum and average distance values computed with respect to AutoPeak-env. $M_{\mathrm{am}}, D_{\mathrm{am}}$ : Mean of all maximum and average distance values computed with respect to AutoPeak-ave. $\mathrm{E}_{\mathrm{m}}, C_{\mathrm{m}}$ : Grand average of all mean efficiency and mean complexity values in percentage. $M_{\mathrm{m}}, D_{\mathrm{m}}$ : Average of mean of all maximum and average distance values with respect to both autopeaks. $M_{\mathrm{c}}, D_{\mathrm{c}}$ : Scaling of $M_{\mathrm{m}}$ and $D_{\mathrm{m}}$ by $C_{\mathrm{m}}$.

\begin{tabular}{|c|c|c|c|c|c|c|c|c|c|c|}
\hline & $M_{\mathrm{em}}$ & $D_{\mathrm{em}}$ & $M_{\mathrm{am}}$ & $D_{\mathrm{am}}$ & $\mathrm{E}_{\mathrm{m}}$ & $C_{\mathrm{m}}$ & $M_{\mathrm{m}}$ & $D_{\mathrm{m}}$ & $M_{\mathrm{c}}$ & $D_{\mathrm{c}}$ \\
\hline \multicolumn{11}{|l|}{128 files (Hc) } \\
\hline YAEU & 0.99 & 0.35 & 1.03 & 0.39 & 97.62 & 74.31 & 1.01 & 0.37 & 0.75 & 0.28 \\
\hline Mus2 & 0.75 & 0.32 & 0.74 & 0.32 & 71.42 & 85.95 & 0.74 & 0.32 & 0.64 & 0.28 \\
\hline $\mathrm{TK}$ & 1.01 & 0.39 & 1.27 & 0.47 & 95.83 & 83.47 & 1.14 & 0.43 & 0.95 & 0.36 \\
\hline Yarman24 & 0.81 & 0.31 & 0.86 & 0.32 & 89.72 & 69.21 & 0.84 & 0.31 & 0.58 & 0.22 \\
\hline Yavuzoglu48 & 1.03 & 0.47 & 1.05 & 0.51 & 94.15 & 86.58 & 1.04 & 0.49 & 0.90 & 0.42 \\
\hline \multicolumn{11}{|c|}{128 files (cents) } \\
\hline YAEU & 22.4 & 7.9 & 23.3 & 8.8 & 97.62 & 74.31 & 22.9 & 8.4 & 17.0 & 6.3 \\
\hline Mus2 & 17.0 & 7.2 & 16.8 & 7.2 & 71.42 & 85.95 & 16.8 & 7.2 & 14.5 & 6.3 \\
\hline TK & 22.9 & 8.8 & 28.8 & 10.6 & 95.83 & 83.47 & 25.8 & 9.7 & 21.5 & 8.2 \\
\hline Yarman24 & 18.3 & 7.0 & 19.5 & 7.2 & 89.72 & 69.21 & 19.0 & 7.0 & 13.1 & 5.0 \\
\hline Yavuzoglu48 & 23.3 & 10.6 & 23.8 & 11.5 & 94.15 & 86.58 & 23.5 & 11.1 & 20.4 & 9.5 \\
\hline
\end{tabular}


signify a hypothetical case where all the theoretical models are scaled to possess the same number of tones per octave. Such a hypothetical case helps us picture which of the theorized scales would perform best if the complexity was even for all the competitors.

For 128 recordings in maqams Rast, Nihavend, Kürdilihicazkar, Uş̧ak, Hüseyni, Hicaz, Saba, Segah and Hüzzam, Mus2 and Yarman24 produce the best scores with regard to the mean of maximum and average absolute errors from AutoPeak-env. and AutoPeak-ave. and their mean $M_{\mathrm{m}}, D_{\mathrm{m}}$. The advantage of the Holderian comma resolution to Mus2 is clear. Nevertheless, Yarman24, with less than half the number of tones per octave compared to Mus2, and despite the unfair scoring in Kürdilihicazkar, yields highly satisfactory results and performs better than its closest competitor YAEU (particularly in Rast, Ussak, Hüseyni, Saba, Segah and Hüzzam). As expected, Yarman24's grand average of all mean complexities is the lowest.

We find it concerning that TK, with a fewer number of tones per octave compared to Yavuzoğlu48 and Mus2, produced the most mediocre scores. This somewhat justifies the criticisms pitted against it. However, it is obvious that the inferior competence of TK is mostly due to inappropriate tone selections. In other words, TK could not correctly determine which scale tones out of its 41-tone tuning it should employ for several maqams. Even so, this is a serious shortcoming.

A graver issue is that, Yavuzoğlu48 cannot do better than YAEU despite possessing twice the number of tones per octave, and cannot accomplish nearly as much as Mus2 even though featuring a voluminous resolution only 5 tones short of logarithmically 53 equal tones to the octave. Just a glimpse at the grand average of all mean complexities reveals that Yavuzoğlu48 is a more complex theoretical model than Mus2. Indeed, it is the most complex model in our study.

A brief look at the grand average of all mean efficiencies reveals that better scores are more or less inversely proportional to $E_{\mathrm{m}}$. In short, greater efficiency does not necessarily signify a positive aspect of theorized scales. Nevertheless, YAEU and Yarman24 are very efficient with their scales given the simplicity with their tunings compared to Mus2.

In contrast, we regard the complexity measure important and utilize it for the scaling of all theoretical models to a hypothetical equalness in size via which we can compare them on an even competing ground. $M_{\mathrm{c}}$ and $D_{\mathrm{c}}$ values portray a speculative situation regarding how well the theoretical models in question would match pitch measurements were they in possession of the same number of tones per octave.

This operation turns the tables over and raises Yarman24 to the top position with Mus2 in close pursuit. The rest of the ranking is still the same, YAEU is still the third while TK and Yavuzoğlu48 are equally wanting.

In conclusion, Mus2 and Yarman24 are highly preferable tuning options for fixed-pitch instruments such as kanun and tanbur for the given set of data on Turkish Maqam music practice superseding by far YAEU, TK and Yavuzoğlu48. For a great amount of detail and the ability to transpose to every degree faultlessly, 'Mercator's cycle' utilized by Mus2 is the obvious choice. For conformity to 24 tones per octave, an easier learning curve, and the ability to satisfactorily represent problematic fickle tones in maqams such as Uşsak, Saba, Hüzzam and Karciğar with less than 1 Holderian comma maximum deviation, the obvious choice is Yarman24.

\section{Acknowledgement}

Barış Bozkurt and M. Kemal Karaosmanoğlu are partially supported by Scientific and Technological Research Council of Türkiye, TÜBITTAK (Project No: 107E024). We would like to also thank Ali Cenk Gedik for his help in construction of the audio database.

\section{References}

Akan, E. (2007). Tanbur metodu. İstanbul: Çağlar Musiki Yayınları.

Akkoç, C. (2002). Non-deterministic scales used in traditional Turkish music. Journal of New Music Research, 31(4), 285-293.

Arel, H.S. (1930/1968). Türk Musikisi Nazariyati Dersleri. İstanbul: Hüsnütabiat Matbaas1.

Arslan, F. (2007). Safiyüddin-i Urmevi ve erefiyye Risalesi. Ankara: Atatürk Kültür Merkezi Yayını.

Barbieri, P. (2008). Enharmonic Instruments And Music: 1470-1900. Rome: Latina, Il Levante Libreria Editrice.

Bozkurt, B. (2008). An automatic pitch analysis method for Turkish Maqam music. Journal of New Music Research, 37(1), 1-13.

Bozkurt, B.B., Gedik, A.C. \& Karaosmanoğlu, M.K. (2008). TMVB: Klasik Türk Müziği İcra Analiz Çalişmaları İçin Bir Veri Bankası. In Proceedings from Türk Müziğinde Uygulama-Kuram Sorunlari ve Çözümleri (Invited Paper), Maçka, İstanbul.

Chalmers, J. (1992). Divisions of the Tetrachord. L. Polansky \& C. Scholz (Eds.). Lebanon, NH: Frog Peak Music Publication.

de Cheveigne, A. \& Kawahara, H. (2002). YIN, a fundamental frequency estimator for speech and music. Journal of the Acoustical Society of America, 111(4), 1917-1930.

Daloğlu, Y. (1985). Tefhim-ü 1-Makamat fi Tevlid-i nNegamat. Graduate Study, Dokuz Eylül University, Fine Arts Faculty, İzmir.

Erguner, S. (2003). Rauf Yekta Bey. İstanbul: Kitabevi. 
Ezgi, S.Z. (1933). Nazari ve Ameli Türk Musıkisi (Vol. I). İstanbul: Milli Mecmua Matbaas1.

Ezgi, S.Z. (1940). Nazari ve Ameli Türk Musıkisi (Vol. IV). İstanbul: Milli Mecmua Matbaas1.

Helmholtz, H.L.F. (1877). On the Sensations of Tone (A.J. Ellis, Trans. \& Ed., 1885) (2nd rev. ed.). New York: Dover Publications.

Hines, J.E. (2009). Retrieved June 1, 2009, from website: http://www.hinesmusic. com/What_Are_Makams.html

Ibn Sina (2004). Mûsikî (A.H. Turabi, Trans.). İstanbul: Litera Yayıncılık (Original work published ca. 1030).

İlerici, K. (1970/1981). Türk Müziği Ve Armonisi. İstanbul: Milli Eğitim Basımevi.

Kantemir, D. (1698). Kitabu 'İmi'l-Mustki 'ala vechi'lHurufat (Y. Tura, Translit. \& Trans.) (Vol. I). İstanbul: Yapı Kredi Yayınları.

Karadeniz, M.E. (1965/1983). Türk Musıkisinin Nazariye ve Esasları. İstanbul: İş Bankası Yayınları.

Karaosmanoğlu, M.K. \& Akkoç, C. (2003). Türk mus ikisinde icra-teori birliğini sağlama yolunda bir girişim. In Proceedings from 10th Müzdak Symposium, Maçka, Istanbul.

Karaosmanoğlu, M.K. (2004). Türk musikisi perdelerini ölçüm, analiz ve test teknikleri. In Proceedings from Türk Müziği Geleneksel Perdelerini Calabilen Piyano İmâli Projesi presentation, Yıldız Teknik Üniversitesi, İstanbul.

Kutluğ, Y.F. (2000). Türk Musikisinde Makamlar (Vol. I). İstanbul: Yapı Kredi Yayınları.

Monzo, J. (2005). Tonalsoft Encyclopedia of Microtonal Music-Theory. Retrieved September 18, 2008, from http://tonalsoft.com/enc/encyclopedia.aspx

Nasır Dede, A. (1796). Tedkik u Tahkik (Y. Tura, Trans. \& Ed.). İstanbul: Tura Yayınları.

Oransay, G. (1959). Das Tonsystem Der Türkei-Türkischen Kunstmusik. Die Musikforschung, 10, 250-264.

Özkan, İ.H. (1998). Türk Musikisi Kuramsalı ve UsûlleriKudüm Velveleleri. İstanbul: Ötüken Neşriyat.

Powers, H. (1988). First meeting of the ICTM Study Group on maqam. Yearbook for Traditional Music, 20, 199-218.

Sada: Niyazi Sayın. (2001). [CD] Mega Müzik-İstanbul.

Sezikli, U. (2000). Kırşehirli Nizameddin İbn Yusuf'un Risale-i Musiki Adlı Eseri. Master thesis, Marmara University, Turkey.

Signell K. (1977). Makam - Modal Practice in Turkish Art Music. Washington: Asian Music Publications.

Tanrıkorur, C. (2004). Türk Müziğ i Kimliği. İstanbul: Dergah Yayınları.

Touma, H.H. (1971). The maqam phenomenon: An improvisation technique in the music of the Middle East. Ethnomusicology, 15(1), 38-48.

Touma, H.H. 1999. The Music of the Arabs (L. Schwartz, Trans. \& Ed.). Portland: Amadeus Press (Original work published 1934).

Tulgan, Ö. (2007). Makam musikisi perdelerinin sirr1, dedüktif bir deneme. Müzik ve Bilim, 7.

Uysal, B.Y. (2001). Türk Gelenek Mustkisi ve Sistem Dokunga. İstanbul: Enes Basimevi.
Yahya, G. (2002). Yorgo Bacanos'un Ud Taksimleri. Ankara: T.C. Kültür Bakanlığı Yayınları.

Yarman, O. (2007). A comparative evaluation of pitch notations in Turkish makam music. Journal of Interdisciplinary Music Studies, 1(2), 43-61.

Yarman, O. (2008). 79-tone tuning \& theory for Turkish maqam music. $\mathrm{PhD}$ thesis, İstanbul Technical University, Turkey.

Yarman, O. (2009). Arel-Ezgi-Uzdilek Sistemine Alternatif, 24-Sesli, Islah Edilmiş Ortaton Temperamanı Temelli Ve Basit Oranlı Bir Düzen. Publication pending (müzik ve bilim dergisi). Retrieved August 25, 2009, from http:// www.ozanyarman.com/files/yarman24.com

Yavuzoğlu, N. (1991). Türk Müziğinde Tanpereman. İstanbul: Türk Musıkisi Vakfı Yayınları.

Yavuzoğlu, N. (2008). 21. Yüzyılda Türk Müzĭ̆l Teorisi. İstanbul: Pan Yayıncilik.

Yekta, R. (1922/1986). Türk Musikisi (O. Nasuhioğlu, Trans.). İstanbul: Pan Yayıncilık.

Yekta, R. (1929). Türk Musikisi Nazariyatı (G. Paçacı, Translit.). Musikisinas, 9, 8-17.

Zannos, I. (1990). Intonation in theory and practice of Greek and Turkish music. Yearbook for Traditional Music, 22, 42-59.

Zeren, A. (2003). Müzik Sorunlarımız Üzerine Arastırmalar. İstanbul: Pan Yayıncilık.

\section{Appendix: Mus2}

According to the official Turkish Maqam music theory (the AEU system), there are only 24 notes in an octave. But starting with Mildan Niyazi Ayomak (1888-1947) some theorists (for instance, Özkan, 1998) pointed out that tones of Turkish Maqam music (perdes) must be interpreted within the context of 53 commas to the octave. However, these theorists are not concerned with which specific notes are required of a given maqam. They only provide additional information such as: "this note is played 1-2 comma flat or sharp with respect to the note indicated on the staff'.

A more direct method of projecting microtonal information is to indicate the comma deviations on the accidentals by way of numerals. This approach has been used in Turkish folk music notation and Kemal İlerici (1970/1981) employed the same method for microtonally harmonizing folk pieces. Given the existence of a large collection of scores produced this way, it is possible to statistically analyse the pitches used for each maqam.

Mus2, a special Maqam music notation program, makes it possible to prepare scores of Turkish music pieces and play them in 53-tone equal octave temperament on a computer. Nearly 2000 Turkish music pieces were notated and AEU tones were calibrated by Holderian commas interactively using this program in order to achieve as close a rendition of actual practice as possible. Most of the scores were notated in a form where 


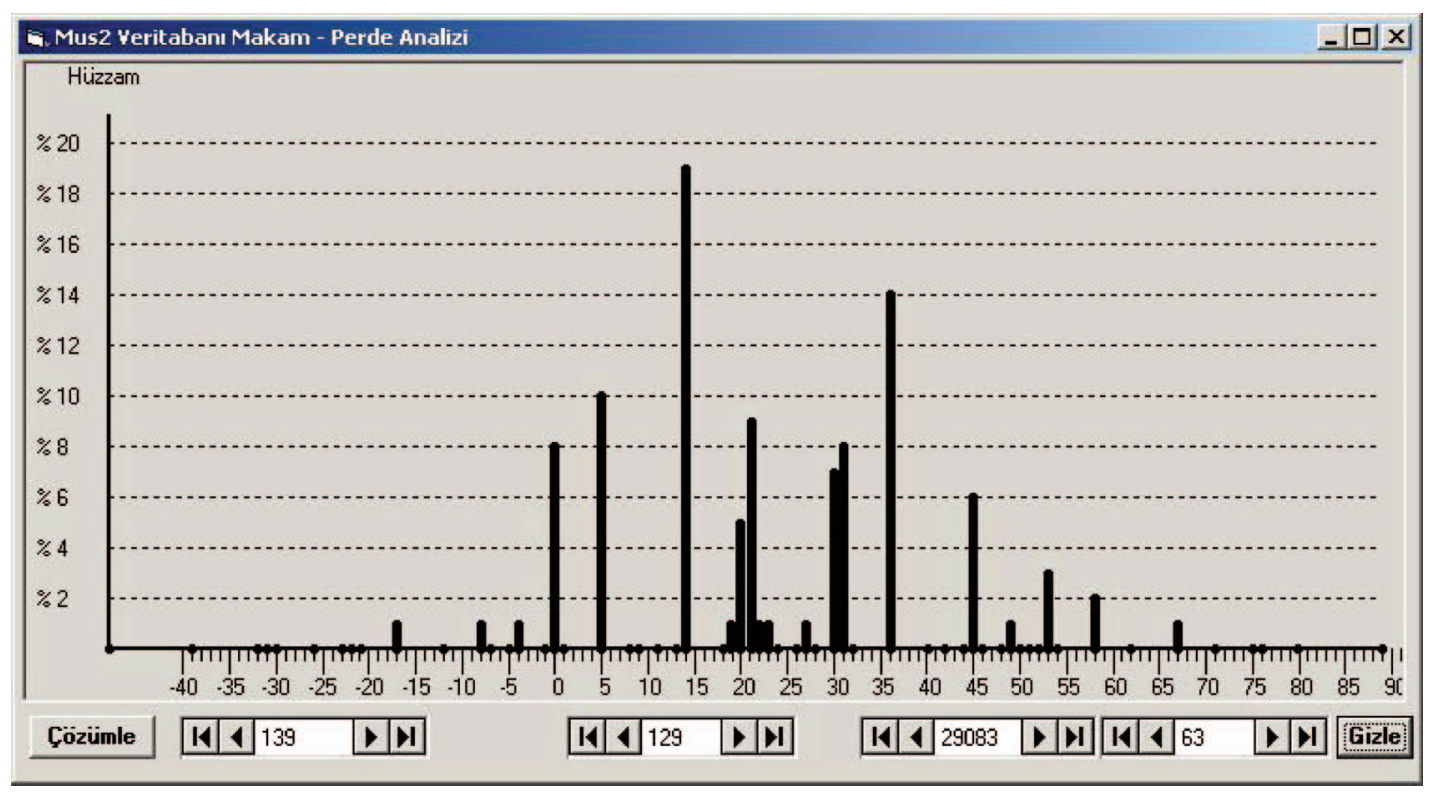

Fig. 13. The distribution of distinct relative pitches for a total of 129 pieces (29083 notes) in maqam Hüzzam in the Mus2 database.

the comma values on AEU accidentals were indicated. Sharps and flats were attached comma numbers not only on key signatures, but also on altered notes. These scores have been used by members of Çirağan Musiki Derneği, an amateur music society. Later on, these music sheets were published by Nota Yayıncılık (www.notamuzik. com) as a series of 20 fascicles, alas without the comma numerals on AEU accidentals due to commercial considerations, but with accompanying CDs featuring original 53-tone equal octave temperament based audio tracks synthesized from MIDI sounds.

Mus2 maqam scales in the figures of this paper were obtained from analysing the Mus2 collection. Scores in the Mus2 database are in 139 different maqams. For example, 129 of nearly 2000 pieces are in maqam Hüzzam, and these pieces comprise 63 distinct pitches in a total of 29,083 notes. In Figure 13, the distribution of distinct relative pitches in pieces composed in maqam Hüzzam is shown.

The horizontal axis indicates the relative pitch in $\mathrm{Hc}$ with respect to the tonic (segâh note/tone (perde) for maqam Hüzzam). The most frequently used note is nevâ at $14 \mathrm{Hc}$ distance to the tonic, then gerdâniye at $36 \mathrm{Hc}$, and then çargâh at $5 \mathrm{Hc}$, etc. The clustering regions around $20 \mathrm{Hc}$ and $30 \mathrm{Hc}$ (hisâr and eviç) can be explained in the following manner: Hisâr is represented in AEU notation as a flattened hüseyni (E) note using a 4-comma slashed flat sign. However, all musicians agree that hisâr is not that flat, but characteristically only 2 commas flatter. Likewise, evic is not 4, but 3 commas sharper from acem. Also, lots of modulations to different maqams occur in Hüzzam pieces around the neighbourhood of hisâr. Consequently, 1, 2, 3 and 4 comma flats from hüseyni have all been used.

To derive a scale in a given maqam from Mus2, a threshold is applied on the distribution of pitches in the database. Notes with a frequency of occurrence higher than or equal to $\% 2$ of the total amount are retained. The Mus2 maqam scales indicated in Figures 4 to 12 and Tables 1 to 9 are obtained by this approach. 